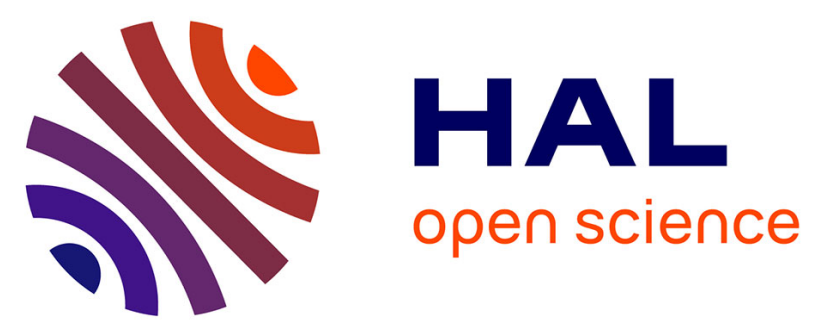

\title{
A model for large glacial-interglacial climate-induced changes in dust and sea salt concentrations in deep ice cores (central Antarctica): palaeoclimatic implications and prospects for refining ice core chronologies
}

\author{
Jean-Robert Petit, B. Delmonte
}

\section{To cite this version:}

Jean-Robert Petit, B. Delmonte. A model for large glacial-interglacial climate-induced changes in dust and sea salt concentrations in deep ice cores (central Antarctica): palaeoclimatic implications and prospects for refining ice core chronologies. Tellus B - Chemical and Physical Meteorology, 2009, 61 (5), pp.768-790. 10.1111/j.1600-0889.2009.00437.x . insu-00421237

\section{HAL Id: insu-00421237}

https://hal-insu.archives-ouvertes.fr/insu-00421237

Submitted on 22 Jun 2021

HAL is a multi-disciplinary open access archive for the deposit and dissemination of scientific research documents, whether they are published or not. The documents may come from teaching and research institutions in France or abroad, or from public or private research centers.
L'archive ouverte pluridisciplinaire HAL, est destinée au dépôt et à la diffusion de documents scientifiques de niveau recherche, publiés ou non, émanant des établissements d'enseignement et de recherche français ou étrangers, des laboratoires publics ou privés. 


\section{A model for large glacial-interglacial climate- induced changes in dust and sea salt concentrations in deep ice cores (central Antarctica): palaeoclimatic implications and prospects for refining ice core chronologies}

\section{J. R. Petit \& B. Delmonte}

To cite this article: J. R. Petit \& B. Delmonte (2009) A model for large glacial-interglacial climateinduced changes in dust and sea salt concentrations in deep ice cores (central Antarctica): palaeoclimatic implications and prospects for refining ice core chronologies, Tellus B: Chemical and Physical Meteorology, 61:5, 768-790, DOI: 10.1111/j.1600-0889.2009.00437.x

To link to this article: https://doi.org/10.1111/j.1600-0889.2009.00437.x

$$
\begin{aligned}
& \text { (c) } 2009 \text { The Author(s). Published by Taylor \& 册 Published online: } 18 \text { Jan } 2017 . \\
& \text { Francis. }
\end{aligned}
$$




\title{
A model for large glacial-interglacial climate-induced changes in dust and sea salt concentrations in deep ice cores (central Antarctica): palaeoclimatic implications and prospects for refining ice core chronologies
}

\author{
By J. R. PETIT ${ }^{1 *}$ and B. DELM ONTE ${ }^{2},{ }^{1}$ Laboratoire de Glaciologie et Géophysique de l'Environnement, \\ C. N. R. S-Université Joseph Fourier, UMR 51230, BP 96, 38402, St Martin d'Hères Cedex, France; ${ }^{2}$ University \\ Milano-Bicocca-DISAT, Department of Environmental Sciences, Piazza della Scienza 1, 20126 Milano, Italy
}

(Manuscript received 12 June 2008; in final form 17 July 2009)

\begin{abstract}
A semi-empirical model has been developed to reproduce glacial-interglacial changes of continental dust and marine sodium concentrations (factor of $\sim 50$ and $\sim 5$, respectively) observed in inland Antarctic ice cores. The model uses conceptual pathways of aerosols within the high troposphere; assumes the dry deposition of impurities on the Antarctic surface; uses estimates of aerosol transit times taken independent of climate; assumes a temperature-dependent removal process during aerosol pathways from the mid-latitudes. The model is fitted to the data over the last four climate cycles from Vostok and EPICA Dome C Antarctic sites. As temperature is cooling, the aerosol response suggests different modes of climate couplings between latitudes, which can be continuous or below temperature thresholds for sodium and dust, respectively. The model estimates a southern South America dust source activity two to three times higher for glacial periods than for the Holocene and a glacial temperature over the Southern Ocean $3-5{ }^{\circ} \mathrm{C}$ cooler. Both estimates appear consistent with independent observations. After removal of temperature effects, dust and sodium residuals for both sites show orbital frequencies in opposite phase at the precession timescale. Such long-term insolation-related modulation of terrestrial and marine aerosol input, could provide a chemical pacemaker useful for refining ice core chronologies.
\end{abstract}

\section{Introduction}

Ice cores from polar regions span time periods comparable to those of marine sediment records and provide a wealth of complementary information on late Quaternary glacial-interglacial climate and atmospheric changes (Watanabe et al., 2003; EPICA Community Members, 2004; North GRIP Project Members, 2004; Jouzel et al., 2007). Ice core records have confirmed the role of insolation both in climate change and in astronomical theory (Jouzel et al., 2007; and references therein). They have also demonstrated the role of greenhouse gases in past glacialinterglacial climate changes (Lorius et al., 1990; Raynaud et al., 1993) important in the assessment of future climate warming (IPCC, 2007)

Major impurities in polar ice originate from various sources such as oceans and continental landmasses, and are often trans-

\footnotetext{
*Corresponding author.

e-mail: petit@lgge.obs.ujf-grenoble.fr

DOI: $10.1111 /$ j.1600-0889.2009.00437.x
}

ported to the polar regions through the atmosphere over very long distances. They can therefore be used to document the variability of atmospheric circulation patterns in the past. Mineral dust (represented by non-sea salt calcium and insoluble particles) and sea salt (represented by part of the sea salt sodium) are primary aerosols of terrestrial and marine origin, respectively. The variability of their past concentrations can be inferred from the ice core records, providing climatic information that can be considered together with the stable isotope, the preferred proxy for temperature (e.g. Jouzel et al., 1987, 2007). The EPICADome $\mathrm{C}$ ice core provides the longest ( $800 \mathrm{kyr}$ ) climate record to date from polar ice cores (EPICA Community Members, 2004; Wolff et al., 2006; Jouzel et al., 2007; Lambert et al., 2008). While dust and sea salt sodium are generally considered to be chemically inactive and conservative tracers of the atmospheric circulation, they provide potential forcing on climate via their radiative properties (IPCC, 2007). Dust may play a role in marine primary production and in the $\mathrm{CO}_{2}$ cycle via its potential for fertilization by the supply of iron (Martin, 1990). Dust concentrations generally increase (up to a factor of 50-70) as 
temperature decreases, a phenomenon that has been observed in both Greenlandic and Antarctic ice core records (Steffensen, 1997; Petit et al., 1999; Lambert et al., 2008). However, it is still difficult to reproduce such changes over glacial periods in atmospheric general circulation models (AGCMs). Indeed, the ice core records suggest a tight climate-aerosol correlation but due to scarcity of geological evidences, the quantitative assessment of the contribution from different climate factors. (e.g. source, transport, atmospheric cleansing, deposition, etc.) on dust concentration is complicate.

As a result of a series of aeolian processes from sources to polar areas, aerosol concentration in ice depends on a number of factors, all related to some degree to climate. Parameters usually taken into account in AGCM simulations include: (a) aeolian deflation over continents (dust), (b) emission from bubble-bursting over the ocean surface and/or secondary emission from sea ice (sodium), (c) transport with gravitational settling, (d) clouds microphysics such as scavenging, washout and (e) dilution by precipitation. A salient feature of Greenlandic and Antarctic ice core records is the out-of-phase relationship between water stable isotope and aerosol changes (e.g. Legrand et al., 1988; Steffensen, 1997; Ruth et al., 2003; Wolff et al., 2006). During the last glacial period, dust and sodium concentrations in ice cores exceeded typical Holocene levels by a factor of 50-70 and 6-8, respectively. This has been seen in both the Vostok ice core over the last four climatic cycles (Petit et al., 1999) and the EPICA Dome $\mathrm{C}$ ice core over the last eight cycles (EPICA Community Members, 2004; Wolff et al., 2006; Lambert et al., 2008). The Last Glacial Maximum (LGM, circa 20 kyr BP) was characterized by a cooler and drier environment, providing conditions for worldwide aeolian deflation over continents, dust transport, and sedimentation (e.g. Charlesworth, 1957; Pye, 1987; Kohfeld and Harrison, 2001). Ocean sediment cores and polar ice records provide considerable evidence of long-range transport of small-size dust particles. However, deposition rates and the magnitude of their changes with climate show a significant geographical heterogeneity. Large differences in dust fallout exist between mid-latitudes and polar areas. Geological records indicate that the dust flux over mid-latitudes was about three to five times higher than present during the LGM (Kohfeld and Harrison, 2001 and references therein). Model simulations generally reproduce this change (e.g. Mahowald et al., 1999, 2006; Werner et al., 2002), except when dealing with dust enhancement observed from polar ice core records over the LGM (e.g. Joussaume, 1989; Genthon, 1992; Andersen et al., 1998). To explain this, Mahowald et al. (1999, 2006), Andersen et al. (1998) suggested a significant change in dust sources, possibly associated with glacial activity in southern South America. Chylek et al. (2001) suggested a $5{ }^{\circ} \mathrm{C}$ drop in tropical temperature leading to a reduction of the Hadley cell activity and the expansion of deserts outside tropical regions; however this was not further supported by simulations (e.g. Mahowald et al., 1999). Werner et al. (2002) invoked seasonality of precipitation amplified by vegetation feedback mechanism to account for the periods of dust enhancement.

Alternatively, Hansson $(1995,1996)$ discussed the possible effects of changes in atmospheric cleansing on impurity contents in Greenland ice records. Fuhrer et al. (1999) and Fischer et al. (2007a) applied it and proposed an atmospheric life-time parameter accounting for an increase in dust concentrations by only a factor of about two. Yung et al. (1996) and Lunt and Valdes (2001) also noted the importance of the reduced removal rate (scavenging) on the dust concentration in air and in the ice. Yung et al. (1996) found that a 50\% reduction in the hydrological cycle in their 2-D model changed the dust concentration over Antarctica by a factor 5. Yung et al. (1996) determined that their results were sensitive to aerosol life-time, along with changes in other factors (e.g. accumulation, wind, source, etc.). Near and downwind of sources, dust fallout is driven by the gravitational settling of large particles, and between LGM and warm climate, simulations of the dust cycle (e.g. Werner et al., 2002) provide only modest changes in the overall life-time. Therefore, the small dust particles that reach the Antarctic plateau, are the particles for which settling is least effective. With a mode around $1 \mu \mathrm{m}$ radius (Steffensen, 1997; Delmonte et al., 2002) the corresponding dry deposition life-time (dominated by the gravitational settling) is from 80 to 300 days (e.g. Mahowald et al., 2006 and reference therein).

For sodium concentrations in ice, it has been suggested that frost flowers that form on new sea ice around Antarctica are a source for sodium aerosol for costal areas and likely for inland sites (Rankin et al., 2002; Wolff et al., 2003, 2006; Fischer et al., 2007a,b). For LGM, the sea ice extent during winter was up to twice as large, possibly explaining the observed sodium flux increase into the Antarctic atmosphere by a similar factor. However, sodium and dust share a part of the atmospheric cycle and the small size sodium aerosol reaching inland sites possibly makes sodium fallout more sensitive to en route atmospheric cleansing. The link with source areas is therefore not straightforward.

Here we will review dust and sodium data from EPICA Dome $\mathrm{C}\left(75^{\circ} 06^{\prime} \mathrm{S}, 123^{\circ} 21^{\prime} \mathrm{E}, 3233 \mathrm{~m}\right.$ a.s.1.), hereafter referred to as EDC, and Vostok $\left(78^{\circ} \mathrm{S}, 106^{\circ} \mathrm{E}, 3488 \mathrm{~m}\right.$ a.s.l.) deep ice cores drilled in central East Antarctica with the objective of reproducing their glacial-interglacial changes (Fig. 1). We use a semiempirical model based on aerosols properties that are fitted from correlations with stable isotope content to determine the main climatic factors influencing aerosol concentration in ice.

Data, model, and hypotheses are presented in Section 2. The available data for the two sites are presented (Section 2.1), then a schematic concept of the atmospheric circulation and for the pathway of dust and sodium from their sources to Antarctica (Section 2.2). The model for impurity concentrations in ice is presented (Section 2.3) and we consider the different climatic factors from ice core data back to the source emission. The snow accumulation rate is first involved to calculate the flux 
EPICA
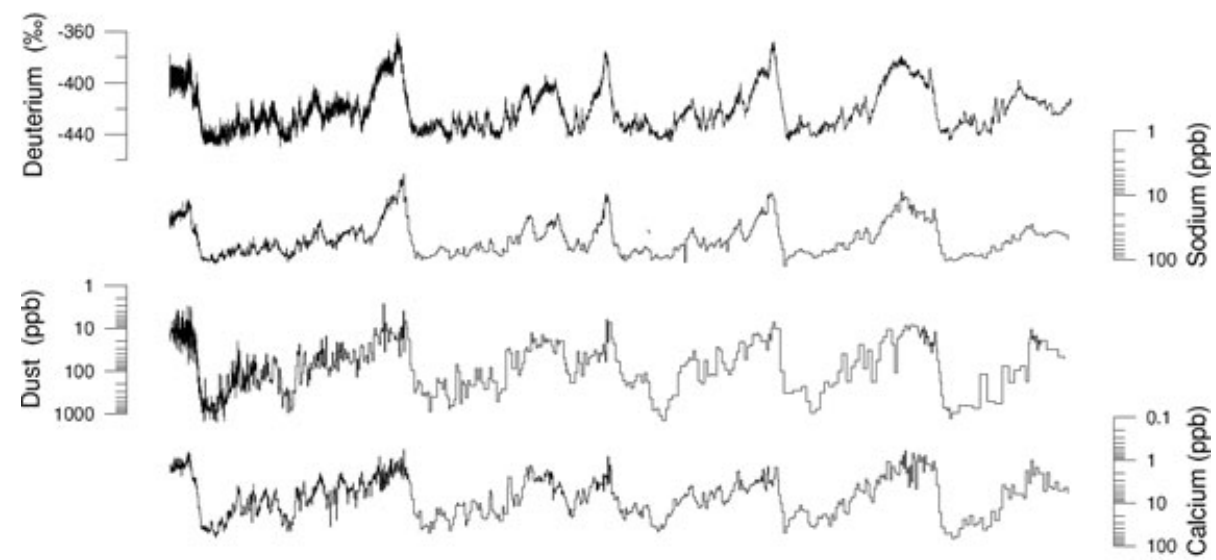

Vostok
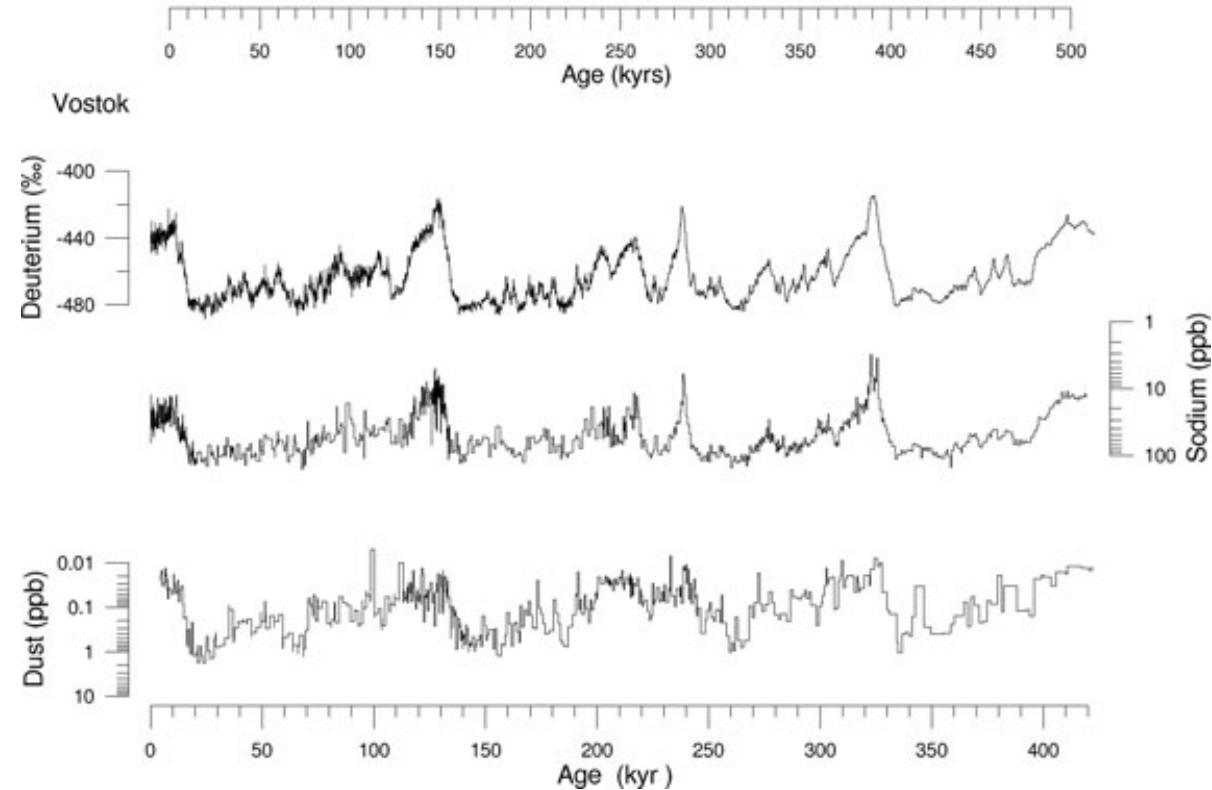

Fig. 1. Antarctic records for climate and aerosols from EPICA Dome C and Vostok (Petit et al., 1999; EPICA Community Members, 2004; Wolff et al., 2006). Upper panel: EPICA Dome C records. From top to bottom: stable isotope content (deuterium \%o w.r.t. SMOW) and sodium, calcium, and dust concentrations (in ppb or $\mathrm{ng} \mathrm{g}^{-1}$ ). Lower panel: Vostok records. From top to bottom: stable isotope content (deuterium), sodium concentration and dust concentration.

(Section 2.4). Then, we estimate a 'mean transit time' for dust and sodium (Section 2.5) and formulate the en route cleansing of aerosol. In Section 3, we use the data to fit the model parameters (Section 3.1 for dust and Section 3.2 for sodium) to evaluate the source changes. A statistical test (chi-square) is used as a complementary method (Section 3.3). Model results and implications are presented in Section 4. The outputs and predictions of the model for dust are compared to independent observations (Section 4.1) and the climatic implications are presented for dust and for sodium (Section 4.2 and 4.3, respectively). Finally, the spectral properties of the residual signals along with their potential implications for ice core dating are presented (Section 4.4) prior the conclusions and further prospects (Section 5).

\section{Data and model}

\subsection{Ice core data}

We use the EDC and Vostok dust, sodium and calcium concentration records, (Fig. 1) and the correlation with the temperature proxy represented by the stable isotope composition of ice $(\delta D \%$ w.r.t. SMOW) for the last four climatic cycles ( $\sim 450 \mathrm{kyr})$. Dust has been measured directly by Coulter Counter or by taking calcium from ion chromatography as proxy. The sodium data are also from ion chromatography (Petit et al., 1999; EPICA Community Members, 2004; Wolff et al., 2006). The ice core dust and chemical data are from discrete ice sample layers approximately $7-55 \mathrm{~cm}$ thick and representative of the 
atmospheric aerosol input to the Antarctic plateau averaged over several years $(\sim 3-50 \mathrm{yr})$ of accumulation. Similarly the isotope data at the corresponding mean depth and time interval cover periods from decades up to a few centuries. The aerosol data can be considered decadal to centennial averages of discrete atmospheric advection events.

Dust concentration increases by up to a factor $\sim 50$ and appear to be more sensitive to changes in temperature during cold periods (i.e. a steeper slope with respect to stable isotope content) thus giving an apparent 'crescent' pattern (Figs $3 \mathrm{~A}_{0}, \mathrm{~B}_{0}$ and $\left.\mathrm{D}_{0}\right)$. This relationship is evident in the EDC record $\left(r^{2} \sim\right.$ 0.73 with 5164 points, Lambert et al., 2008). The marine sodium concentrations, which increase by up to a factor of 5 at EDC and Vostok (data from EPICA Community Members, 2004 and Petit et al., 1999), appear linearly correlated with the isotope content for both sites and show already a high determination coefficient (Figs $3 \mathrm{C}_{0}$ and $\mathrm{E}_{0}, r^{2}=0.76$ and 0.77 for EDC and Vostok, respectively). These correlations show that the marine and the continental aerosol have a different behaviour with respect to climate and to temperature-dependent factors.

\subsection{Conceptual pathways for dust and sodium}

Around Antarctica, the major features of atmospheric circulation are the Westerlies over the Southern Ocean and the permanent cyclonic belt over the polar fronts (e.g. Schwerdtfeger, 1984). Oceanic and atmospheric temperatures are closely coupled. The polar fronts in the ocean and atmosphere mark important climate boundaries in air-sea fluxes and oceanographic water masses. Depending on season, advection of marine air from the Southern Ocean, or from the mid-latitudes, to Antarctica operates at different altitudes. At global scale, air mass pathways are very complex but here assumed to occur along isentropes, so that warm, tropical air to be transported poleward (e.g. Hoskin and Pearce, 1983). Due to a permanent baroclinic difference between low and high latitudes, the warm and wet air from tropical regions is wandering poleward through eddies and ultimately overlying the cold and dry polar air.

The Antarctic surface is very cold and its radiative deficit leads to a surface-based inversion layer a few hundred metres. At the top, marked by a temperature maximum, most of the moisture and latent heat penetrates. By comparison to the ice sheet surface, the amplitude of the seasonal cycle of air temperature at the top of the inversion layer is smaller (Schwerdtfeger, 1984). Similarly the mean glacial-interglacial temperature change deduced from the stable isotope composition of ice core samples, is about $5-7^{\circ} \mathrm{C}$ at the top of the inversion layer, compared to $8-10^{\circ} \mathrm{C}$ at the ice sheet surface (Stenni et al., 2002).

The atmospheric cycle of dust and sodium is shown in Fig. 2. The sources of dust for East Antarctica are the southern hemisphere continents; the contribution of southern South America was dominant during the late Quaternary glacial periods (e.g.
Delmonte et al., 2004b; and references therein). Dust transported to Antarctica from South America need to be lifted to altitudes greater than $4000 \mathrm{~m}$ a.s.l., well above the marine boundary layer; otherwise will be efficiently washed out. Continental air masses can reach 8-10 km altitude over South America (Ramonet et al., 1996). The small dust particles from southern America likely follow a long and complex trajectory at high altitude prior to reaching the Antarctic plateau. Conversely, the visible, coarsegrained ash layers that are sometimes observed in ice cores mostly originate from eruptives centres surrounding Antarctica, and were likely subjected to favourable rapid atmospheric transport through the low troposphere (Narcisi et al., 2005).

Between glacial and interglacial periods, the continental dust particles found in different Antarctic ice records over the plateau, display a size distribution mode value of around $2 \mu \mathrm{m}$ (diameter), which could be considered a constant property. In AGCMs, the corresponding dry deposition life-time is at least an order of magnitude larger than wet deposition life-time ( $>80 \mathrm{~d}$ and $\sim 8 \mathrm{~d}$, respectively, Mahowald et al., 2006). Indeed, the small variability in observed size distribution mode (e.g. from 1.8 to $2.2 \mu \mathrm{m}$ ) was associated to the variability, at regional scale, of the strength of the subsidence over Antarctica. Subsidence variations could influence the air inflow from the low latitudes (Delmonte et al., 2004a; Lambert et al., 2008). The constant size distribution of Antarctic dust implies that the gravitational settling is independent of climate or compensated for by an overall constant atmospheric transport.

Our model assumes that transport takes place within hightropospheric pathways over the Southern Ocean (e.g. from $4000 \mathrm{~m}$ altitude up to the top of the tropopause). While cleansing by precipitation generally represents the major removal process, it becomes negligible with respect to dry deposition in the Antarctic troposphere where air subsidence likely dominates. Sodium sources are the open ocean and the sea salt re-emission from sea ice or a combination of both. Whatever the sodium source, once injected to high altitudes, sodium aerosols are transported poleward and inland by atmospheric circulation. As for dust, cleansing by precipitation is an important removal process along the tropospheric pathway over the ocean and negligible in the dry cold troposphere over the Antarctic.

\subsection{Model for impurity concentrations in ice}

The range of variability observed for concentrations (e.g. dust) in ice covers one or two orders of magnitude, likely a response to changes in several climatic factors acting simultaneously. For aerosols, the concentration may be expressed by a series of different factors such as source emission, long-range transport, synoptic and meteorological situation, atmosphere-snow transfer and possibly the conformity of ice as a continuous record, the analytical noise from ice core processing, etc. Concentration is a positive quantity imposing to the different factors to be positive and to act in multiplicative way. For random positive 


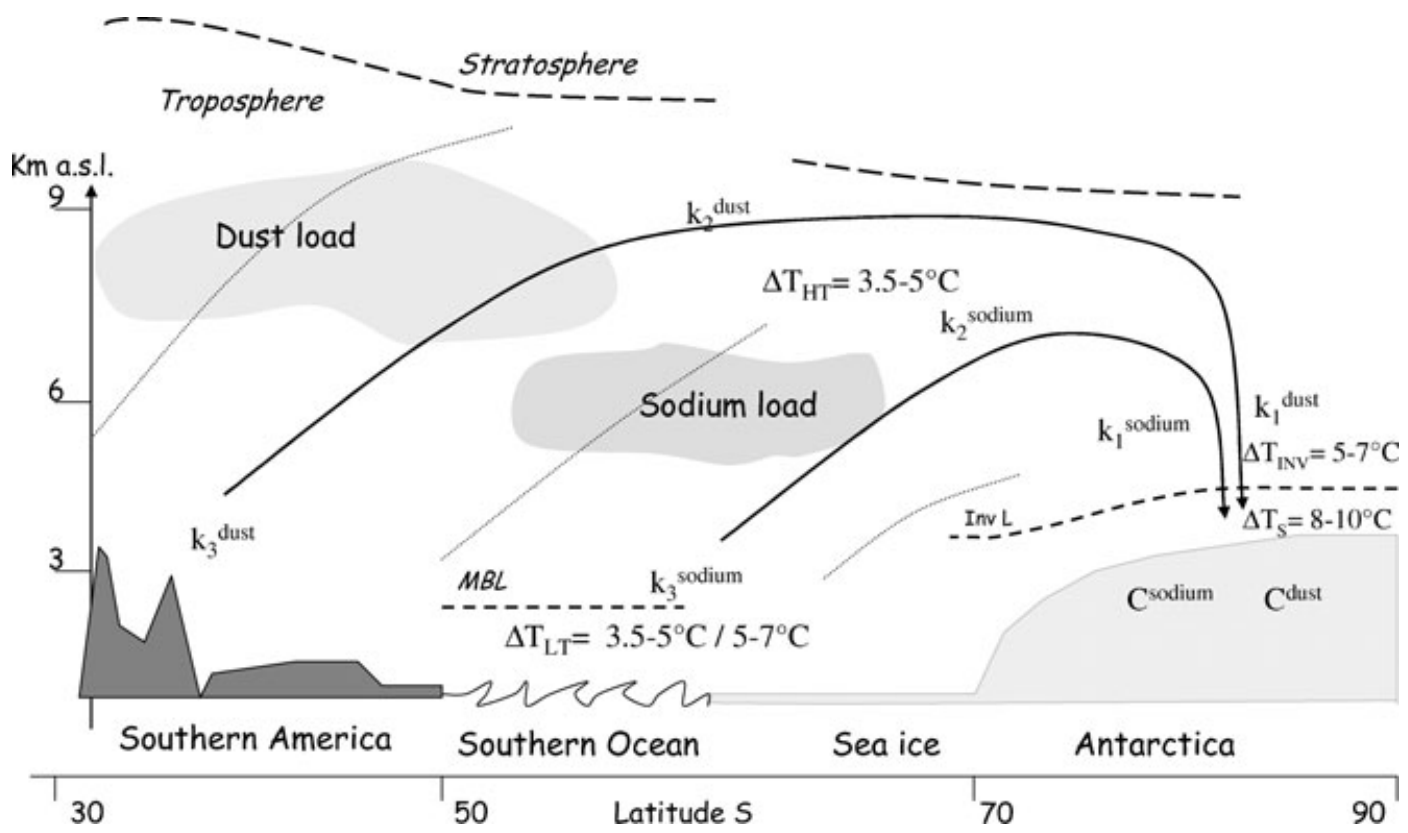

Fig. 2. Conceptual model for the dust and sea salt sodium input onto the Antarctic Plateau. Dust and marine aerosols are uplifted over the marine boundary layer (MBL) then supposed to be transported in between isentropic surfaces (inspired from Hoskins and Pearce, 1983) over Antarctica where they fall down. The elevation (in km above sea level) is given by the scale on the left-hand side. $C^{\text {dust }}$ and $C^{\text {sodium }}$ hold for dust and sodium concentrations in snow; $k_{1}, k_{2}, k_{3}$ (with superscripts for dust and sodium) the different climatic factors (see text). $\Delta T$ is the glacial-interglacial temperature change: $\Delta T_{\mathrm{S}}$ at the surface of Antarctica, $\Delta T_{\mathrm{INV}}$ at the top of the inversion layer (Inv $\mathrm{L}$ ) as deduced from the isotope studies (Stenni et al., 2002). $\Delta T_{\mathrm{HT}}$ and $\Delta T_{\mathrm{LT}}$ are deduced from the model for high and low troposphere levels around Antarctica. High/low $\Delta T_{\mathrm{LT}}$ estimates correspond to high/low sea ice extent (see the text).

factors acting in multiplicative way at given conditions, a lognormal distribution of values would be expected (Aitchison and Brown, 1957). As already done for some chemical impurities in ice (e.g. Castellano et al., 2004), we assume a lognormal probability distribution function for impurity concentrations in ice. The available ice core data represent several years of aerosol fallout recorded sequentially over several climatic cycles. They will be used to investigate the different climatic factors as well as their long-term trends. Considering the climatic factors are dominant, the concentration $(C)$ of a given primary aerosol in ice can be written as

$C=C_{\mathrm{H}} \prod_{i=1}^{i=n} k_{i}$,

where $C_{\mathrm{H}}$ is the mean concentration for reference climate (e.g. over the Holocene) and $k_{i}\left(k_{1}, k_{2}, \ldots, k_{n}\right)$ the different climatic factors. The logarithm (natural) of the concentration ratio with respect to the Holocene value can be written as

$\operatorname{Ln}\left(C / C_{\mathrm{H}}\right)=\sum_{i=1}^{i=n} K_{i}$

with $K_{i}=\operatorname{Ln} k_{i}$
The residuals we can deduce $\left(R_{1}, R_{2}, \ldots, R_{n}\right)$ are calculated at each step as factors $K_{1}, K_{2}, \ldots, K_{n}$ are introduced, giving

$R_{n}=\operatorname{Ln}\left(C / C_{\mathrm{H}}\right)-\sum_{i=1}^{i=n} K_{i}$.

The aim is to minimize $R_{n}$ to be close to a Gaussian noise. Available sequential ice core data allow to explore, the variance of the residuals $\left(R_{1}, R_{2}, \ldots, R_{n}\right)$ with respect to isotope content (i.e. in the temperature domain), and with respect to time (i.e. in the time domain). The climatic factors will be expressed by different functions of the isotope content.

\subsection{Assumption for dry deposition over the Antarctic plateau}

Over the Antarctic plateau, due to the very low precipitation rate, dry deposition of the aerosol dominates (Legrand and Mayewski, 1997 and references therein). The amount of snow precipitation (i.e. accumulation rate) is therefore taken as the first factor influencing the aerosol concentration in Antarctic ice acting by simple dilution of the aerosol fallout. The aerosol flux (product of the concentration and accumulation rate) is considered to be more representative than concentration for the atmospheric load (Wolff et al., 2006 and references therein). This may be 
not the case for polar sites with higher accumulation rates such as Greenland, where wet deposition is more important and the atmospheric load is better represented by the ice concentration (Alley et al., 1995). For central Antarctic sites, we therefore assigned the first climatic factor $\left(k_{1}\right.$ in eq. 1$)$ to the dry deposition or equivalently to the snow accumulation. The dry deposition/accumulation factor $\left(k_{1}\right)$ will be represented by the ratio of the mean Holocene accumulation rate $\left(A_{\mathrm{H}}\right)$ to the accumulation rate of a given period (Acc). The accumulation rate depends on the atmospheric vapour content and air temperature, and is usually expressed by an empirical function, inspired from the Clausius-Claperon formula, and expressed versus the isotope content of snow (e.g. Ritz, 1992, Parrenin et al., 2001). It is written as

$k_{1}=A_{\mathrm{H}} / A c c=\exp \left[-\eta \beta\left(\delta D-\delta D_{\mathrm{H}}\right)\right]$,

where $\delta D$ and $\delta D_{\mathrm{H}}$ is the isotope content for a given period and the mean Holocene value, respectively. Parameter $(\beta)$ is empirically imposed from glaciological models used for ice core dating, and constrained to fit some time markers ( $\beta$ is 0.0157 for EDC, Parrenin et al., 2007). Here we introduce a variable parameter $(\eta)$ representing the ratio of temperature change between a given troposphere level for regions outside central Antarctica and the temperature at the top inversion layer over the plateau. It will be further used for other climatic factors less directly associated with Antarctic temperature. For the dry deposition/ accumulation factor $\left(k_{1}\right), \eta$ equals 1 . Assuming a mean accumulation rate up to two times lower during the maximum of glacial periods than in warm periods such as the Holocene (e.g. Schwander et al., 2001), the increase in the glacial input of dust and calcium for EDC and Vostok compared to the mean Holocene level is reduced from a factor of $\sim 50$ down to $\sim 25$ (Delmonte at al., 2002; Bigler et al., 2006; Lambert et al., 2008) and from a factor of $\sim 5$ down to 2.5 for sodium (Wolf et al., 2006).

When we consider the calculated variances and geometric standard deviation of the residuals $R_{1}$, we find they are still substantial ( $\sigma_{\mathrm{g}} \sim 3$ and $\sim 1.5$ for dust and sodium, respectively, for EDC, Table 1) both for EDC and Vostok. However, both the dust and sodium fluxes (and residual $R_{1}$ ) still appear to be correlated with the isotope content. Sodium residuals again display a monotonic dependence on isotope content (Figs $3 \mathrm{C}_{1}$ and $E_{1}$ ), while the dust-isotope scatter plot still displays its 'crescent' pattern (Figs $3 \mathrm{~A}_{1}, \mathrm{~B}_{1}$ and $\mathrm{D}_{1}$ ). For both sites, the dust flux appears to be almost constant with respect to the isotope content corresponding to warm conditions, but steadily increases below a threshold value we located around $\sim-405 \%$ for EDC (Figs $3 \mathrm{~A}_{1}$ and $\mathrm{B}_{1}$ ) and $\sim-440 \%$ for Vostok (Fig. $2 \mathrm{D}_{1}$ ).

\subsection{Transit time}

Aerosol transport depends on two main parameters (i) the transit time (transport time or advection time) of air masses from mid-latitudes sources to Antarctica and (ii) the en route removal processes governing the aerosol life-time. Variations in glacial dust and sodium input have often been interpreted in terms of changes in surface wind, atmospheric circulation, and meridional transport over Antarctica (e.g. Petit et al., 1981, 1990, Legrand et al., 1988). However, AGCM experiments predict only modest changes in relation to these factors (e.g. Krinner and Genthon, 1998, 2003). From the observations, the rather constant pattern of the size distribution of the dust in ice cores from different sites on the Antarctic plateau support this view (Delmonte et al., 2004a). We must therefore acknowledge that overall mean transit time is not a dominant factor. We assume the dust and sodium aerosols are transported through different pathways (see the model illustrated in Fig. 2) and their mean transport durations must be estimated.

2.5.1. Mean transit time for dust. We estimated a 'mean transit time' for dust from its concentration over the continental source and the Antarctic atmosphere, as well as from concentrations of ${ }^{222} \mathrm{Rn}$, a radioactive gas (3.82 day half-life) emitted by continents. The atmospheric dust concentration over South Pole station (Admunsen Scott) for the present climate is about $10^{-9} \mathrm{~g} \mathrm{~m}^{-3}$ S.T.P. (Cunningham and Zoller, 1981), about two orders of magnitude lower than that observed over the continents for a similar range of size (i.e. $<5 \mu \mathrm{m}$ ). We associate this ratio to the fate of aerosol content in the atmosphere or to the atmospheric load (Junge, 1963). Considering ' $t+t$ ' to be the mean transit time and ' $\tau$ ' the e-folding time of aerosol, we can write for atmospheric concentrations

$C / C_{0}=\exp \left(-t \_t / \tau\right)$.

Adopting a mean e-folding time $(\tau)$ of about a week for dust in the present climate (Balkanski et al., 1993; Yung et al., 1996), the 'mean transit time' at present would be about one month ( $t_{-} t^{\text {Dust }} / \tau^{\text {Dust }} \sim 4-5$ ). Such a value is indeed supported by ${ }^{222} \mathrm{Rn}$ concentrations (e-folding time of $5.5 \mathrm{~d}$ ) and can be used as a clock for continental air masses, as the e-folding time, life-time and therefore fate in the atmosphere are similar to those of dust. The two order of magnitude difference between the source over subtropics and Antarctica, e.g. 25 and 0.2 pico Curie $\mathrm{m}^{-3}(\sim 800$ and $8 \mathrm{mBq} \mathrm{m}^{-3}$ ), respectively (Maenhaut et al., 1979; Genthon and Armengeaud, 1995; Jacob et al., 1997; Li et al., 2008) provides similar 'mean air mass ages' (22-27 d or 3-4 weeks). For glacial climate, we will assume that the overall transit time remains unchanged, as suggested by the rather constant feature of the dust size distribution, and indirectly by overall weak responses from AGCMs experiments (e.g. Krinner and Genthon, 1998, 2003).

2.5.2. Mean transit time for sodium. Due to shorter atmospheric pathways, the probability of a marine air parcel from the Southern Ocean reaching inner Antarctica should be higher than for a continental air parcel. Overland traverse data indicates that sodium concentrations in snow are low, relative to coastal sites and almost constant in central regions (De Angelis, 
Table 1. Data properties for EPICA Dome C and Vostok ice records

\begin{tabular}{lccccc}
\hline EPICA sodium & & & & \\
\hline Nb of data & \multicolumn{2}{c}{1278} & & & \\
Holocene concentration (ppb) & \multicolumn{2}{c}{21.4} & & & \\
Overall mean concentration (ppb) & & 49.6 & & & \\
\hline & $r^{2}$ & $\sigma^{2}$ & $\%$ Variance & $\%$ Explained & $\sigma_{\mathrm{g}}$ \\
\hline$R$ & 0.91 & 0.38 & 100 & 0 & 1.86 \\
$R_{1}$ & 0.74 & 0.13 & 34 & 66 & 1.44 \\
$R_{2}$ & 0.00 & 0.03 & 8 & 92 & 1.20 \\
& & & & & \\
\hline
\end{tabular}

Vostok sodium

\begin{tabular}{lcccrr}
\hline Nb of data & 948 & & & & \\
Holocene concentration $(\mathrm{ppb})$ & 27.7 & & & & \\
Overall mean concentration $(\mathrm{ppb})$ & 57.9 & & & & \\
\hline & $r^{2}$ & $\sigma^{2}$ & $\%$ Variance & $\%$ Explained & $\sigma_{\mathrm{g}}$ \\
\hline$R$ & 0.76 & 0.51 & 100 & 0 & 2.04 \\
$R_{1}$ & 0.52 & 0.25 & 49 & 51 & 1.65 \\
$R_{2}$ & 0.01 & 0.12 & 24 & 76 & 1.41
\end{tabular}

\section{EPICA calcium}

\begin{tabular}{llcccc}
\hline Nb of data & 1279 & & & & \\
Holocene concentration (ppb) & 1.2 & & & & \\
Overall mean concentration (ppb) & 11.3 & & & & \\
ASEF (LGM) & 2.1 & & & & \\
\hline & $r^{2}$ & $\sigma^{2}$ & $\%$ Variance & $\%$ Explained & $\sigma_{\mathrm{g}}$ \\
\hline$R$ & 0.75 & 1.20 & 100 & 0 & 2.99 \\
$R_{1}$ & 0.6 & 0.75 & 63 & 38 & 2.38 \\
$R_{2}$ & 0.06 & 0.29 & 24 & 76 & 1.71 \\
$R_{3}$ & 0.01 & 0.23 & 19 & 81 & 1.62 \\
& & & & & \\
\hline
\end{tabular}

\section{EPICA Dust}

\begin{tabular}{llllll}
\hline Nb of data & 1063 & & & & \\
Holocene concentration (ppb) & 13.5 & & & & \\
Overall mean concentration (ppb) & 155 & & & & \\
ASEF (LGM) & 3.2 & & & & \\
\hline & $r^{2}$ & $\sigma^{2}$ & \% Variance & \% Explained & $\sigma_{\mathrm{g}}$ \\
\hline$R$ & 0.77 & 2.08 & 100 & 0 & 4.23 \\
$R_{1}$ & 0.67 & 1.42 & 68 & 32 & 3.29 \\
$R_{2}$ & 0.24 & 0.57 & 27 & 73 & 2.13 \\
$R_{3}$ & 0.00 & 0.38 & 18 & & \\
& & & & & \\
\hline Vostok Dust & & & & & \\
\hline Nb of data & 696 & & & & \\
Holocene concentration (ppb) & $30(15)$ & & & & \\
Overall mean concentration (ppb) & 180 & & & & \\
ASEF (LGM) & $1.7(2.3)$ & & & & \\
\end{tabular}


Table 1 continued

\begin{tabular}{lccccc}
\hline & $r^{2}$ & $\sigma^{2}$ & $\%$ Variance & $\%$ Explained & $\sigma_{\mathrm{g}}$ \\
\hline$R$ & 0.55 & 1.40 & 100 & 0 & 3.26 \\
$R_{1}$ & 0.40 & 1.03 & 74 & 26 & 2.76 \\
$R_{2}$ & 0.05 & 0.62 & 44 & 56 & 2.20 \\
$R_{3}$ & 0.00 & 0.51 & 36 & 64 & 2.04 \\
\hline
\end{tabular}

Notes: Determination coefficient $\left(r^{2}\right)$ with respect to isotope content, variance $\left(\sigma^{2}\right) ; \%$ of variance, percent of the variance explained by the model and geometric standard deviation $\sigma_{\mathrm{g}}$ for residuals. $\sigma_{\mathrm{g}}$ is given by $\exp (\sigma)$ and confidence interval at one sigma around a mean value $M$ is $\left[M / \sigma_{\mathrm{g}} ; M \sigma_{\mathrm{g}}\right]$. For Vostok dust, ASEF was calculated with the measured Holocene value of $30 \mathrm{ppb}$ (likely overestimated because of the poor quality of the core) and with a value of $15 \mathrm{ppb}$ (in brackets). EPICA sodium and calcium concentration data are from Wolff et al. (2006) and the dust data are from EPICA Community members (2004). Vostok dust and sodium data are from Petit et al. (1999). While non-sea salt sodium and terrigenous calcium would be more appropriate for correlations, we used the available total sodium and calcium concentrations that introduce a bias of minor importance.

personal communication, 2008). This suggests an inland decrease of atmospheric load (i.e. aerosol flux) and supports our dry deposition assumption. Adopting a value of $C / C_{0}$ (in eq. 5) for marine aerosol, 10 times greater than for dust (i.e. 0.1 ), we infer a value of about $1.5-2$ for the $t_{-} t^{\text {Sodium }} / \tau^{\text {Sodium }}$ parameter. With $\tau^{\text {Sodium }}=3 \mathrm{~d}$, the mean transit time $t_{-} t^{\text {Sodium }}$ would be 4. 5-7 d, a value similar to, though slightly higher than, those from back trajectory reconstructions for present 'meteorological' conditions (Reijmer et al., 2002).

\subsection{The e-folding time and climate relationship}

Aerosols over Antarctica represent the background atmospheric aerosol load, a consequence of the remoteness of sources. They represent the remaining part of the initial atmospheric load after the action of removal processes throughout the voyage from the sources (surrounding ocean for sea salt and mid-latitude continental areas for dust) to the pole. Among en route factors, scavenging by wet deposition is likely dominant for aerosol lifetime (e-folding time), while the gravitational settling of micronsize dust particles, as found in ice, is less important. Within the assumption for a constant overall transit time, gravitational settling also becomes independent of climate, and is therefore not considered here.

Wet deposition includes collision and nucleation scavenging, so the atmospheric water content plays a major role in atmospheric cleansing. The aerosol e-folding time $(\tau)$ is taken to be inversely proportional to the precipitation rate, a relationship parametrized in the AGCMs (see Appendix Section A1). Ultimately, the precipitation rate and the atmospheric water content are linked, and in turn associated with the Antarctic temperature (eq. 4). Between a given period in the past and the Holocene (subscript $_{\mathrm{H}}$ ), based on eq. (5), for a given $C_{0}$, a life-time factor $\left(k_{2}\right)$ can be expressed as

$k_{2}=C / C_{\mathrm{H}}=\exp \left[t_{-} t / \tau_{\mathrm{H}}\left(1-\tau_{\mathrm{H}} / \tau\right)\right]$, where $t_{-} t / \tau_{\mathrm{H}}$ for the dust and sodium $\left(t_{-} t^{\text {Dust }} / \tau_{\mathrm{H}}\right.$ Dust and $t_{-} t^{\text {Sodium }} / \tau_{\mathrm{H}}{ }^{\text {Sodium })}$ are about 4 and 2 , respectively. $\tau_{\mathrm{H}} / \tau$ for dust and sodium are given by

$\tau_{H} / \tau=\left(A_{H} / A c c\right)^{-1}=\exp \left[\eta \beta\left(\delta D-\delta D_{H}\right)\right]$.

Between Holocene ( ${ }_{\mathrm{H}}$ ) and Glacial ( ${ }_{\mathrm{G}}$ ) climate, with an $A_{\mathrm{H}} / A_{\mathrm{G}}$ value of $2, \tau_{\mathrm{H}} / \tau_{\mathrm{G}}$ is 0.5 and $k_{2}$ for dust $\left(k_{2}{ }^{\text {Dust }}\right)$ is $\sim 7$ for the concentration changes. This estimate is similar to that of Yung et al. (1996), while the parameter ' $\eta$ ' of eq. (7) is equal to 1 . This could be refined to better fit the data. Applied to sodium and with a glacial e-folding time changing from 3 to $7 \mathrm{~d}, t_{-} t^{\text {Sodium }} / \tau_{\mathrm{H}}$ Sodium is 1.5-2; a factor $\sim 2$ is inferred for $k_{2}{ }^{\text {sodium }}$ and therefore for the sodium concentration. The life-time factor for sodium would therefore be smaller than for dust (e.g. $\sim 2$ instead of $\sim 7$ ).

\section{Fitting model parameters to ice core data}

\subsection{Dust}

3.1.1. Isotope threshold 1 and life-time factor $\left(k_{2}{ }^{\text {Dust }}\right)$. Once the dry deposition/accumulation factor $\left(k_{1}\right)$ is taken into account, the scatter plot of dust versus isotope content shows an absence of correlation at high isotope values, while a covariance occurs below a first deuterium threshold $\delta D_{1} \sim-405 \%$ for EDC (Figs $3 \mathrm{~A}_{1}$ and $\mathrm{B}_{1}$ ) and $\sim-445 \%$ for Vostok (Fig. $3 \mathrm{D}_{1}$ ). Indeed, for isotope values above $\delta D_{1}$, concentrations are linearly correlated with the accumulation rate and the dust flux over Antarctica is almost constant. In terms of climate, this may reflect the absence of strong links between the troposphere over the Antarctic plateau and the high troposphere over the surrounding ocean through which the dust is transported. For temperatures below $\delta D_{1}$, the two troposphere temperatures co-vary and we assume a change in washout conditions during the long-range transport and a different aerosol e-folding time applies. This is expressed by the life-time factor ( $k_{2}{ }^{\text {Dust }}$ and eq. 6 ). 


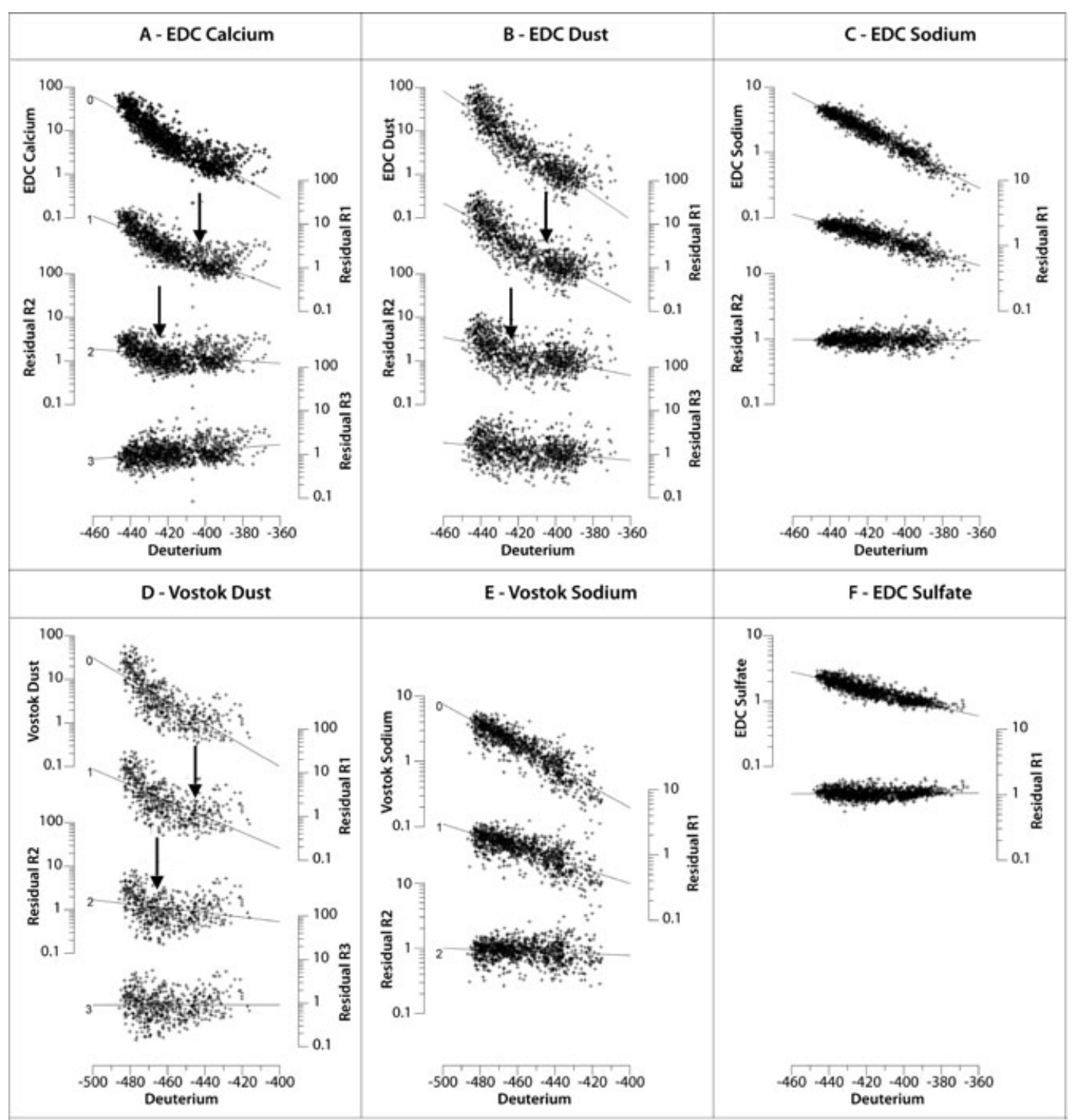

Fig. 3. Scatter plot of impurity concentrations with respect to the isotope content. Panels A-C: calcium, dust, and sodium data from EPICA Dome C. Panels D and E: dust, sodium from Vostok data. Panel F: non-sea salt sulphate data from EPICA Dome C. In each panel the number 0, 1, 2, 3 refer to residual $R_{0}, R_{1}, R_{2}, R_{3}$, respectively. Arrows indicate the different isotope thresholds for dust and calcium (see the text). Regression lines (log-linear) are also shown.

For dust, we use a transit time ( $\left.t_{-} t^{\text {Dust }}\right)$ of 4 weeks and an overall e-folding time $(\tau)$ corresponding to a troposphere temperature along the dust pathway. Applying $k_{2}$ Dust and eq. (6) below $\delta D_{1}$, the parameter ' $\eta$ ' is adjusted in order to increase the (negative) mean slope of the scatter plot of the dust flux with respect to the isotope content up to zero (Figs $3 \mathrm{~A}_{2}, \mathrm{~B}_{2}$ and $\mathrm{D}_{2}$ ). Indeed, for dust (and also for sodium), considering that the lowest atmospheric aerosol loads over Antarctica occur only for interglacial periods, a minimum value may be defined for the dust and sodium flux onto the Antarctic sites, in turn providing a constraint on the ' $\eta$ ' value. The empirical value $(\eta \sim 0.7)$ we deduce could be the apparent ratio of the change in mean temperature at the troposphere level in which the aerosols were transported to the top inversion layer temperature change over the Antarctic plateau (see discussion).

3.1.2. Isotope threshold 2 and source factor $\left(k_{3}{ }^{\text {Dust }}\right)$. After the $k_{2}$ Dust factor is applied, the residual $R_{2}$ Dust we now obtain indicates that most of the changes are compensated (e.g. the dust flux becomes constant and is similar to the Holocene value) except for the lowest isotope values for which higher concentration ratios (factor $\sim 3$ ) are still present (Figs $3 \mathrm{~A}_{2}, \mathrm{~B}_{2}$ and $\mathrm{D}_{2}$ ). The 'hockey stick' pattern displayed suggests that a new climatic factor affects the dust concentration below a given temperature and a second isotope threshold. This new threshold $\left(\delta D_{2}\right)$ for both calcium and dust is $\sim-425$ and $\sim-465 \%$ for EDC and Vostok, respectively, and corresponds to the inflection point in 
the dust/isotope scatter plot. The $\delta D_{2}$ values correspond also to very cold climate (more than $4{ }^{\circ} \mathrm{C}$ below mean Holocene temperature) and half way to maximum glacial conditions. At this step, the new climatic factor for dust $\left(k_{3}{ }^{\text {Dust }}\right)$, we associate to source change (see discussion), is empirically defined below $\delta D_{2}$ in order to increase the (negative) remaining dust-isotope slope from the scatter plot up to a mean value of zero. It can be written as

$k_{3}^{\text {Dust }}=\exp \left[\gamma\left(\delta D-\delta D_{2}\right)\right]$

where ' $\gamma$ ' is a parameter deduced from the best fit of $R_{2}$ versus isotope values below $\delta D_{2}(\gamma=0.07 \pm 0.01$ for calcium and dust of EDC and Vostok sites). As expected, the next residual $R_{3}{ }^{\text {Dust }}$ obtained no longer covaries with the isotope content (Figs $3 \mathrm{~A}_{3}$, $\mathrm{B}_{3}$ and $\mathrm{D}_{3}$ ) and the first derivative with respect to isotope content is close to zero (i.e. corresponding to an overall almost constant corrected dust flux equivalent to that of interglacial periods).

3.1.3. Model equation. To sum up, the dust concentrations can be fitted by the expression

$$
\begin{aligned}
& \operatorname{Ln}\left(C / C_{\mathrm{H}}\right)=-\beta\left(\delta D-\delta D_{\mathrm{H}}\right)+S_{1}\left(t t_{-} t^{\text {Dust }} / \tau_{\mathrm{H}}^{\text {Dust }}\right) \\
& \quad \times\left\{1-\exp \left[\eta \beta\left(\delta D-\delta D_{1}\right)\right]\right\}-S 2 \gamma\left(\delta D-\delta D_{2}\right)+R_{3}^{\text {Dust }}
\end{aligned}
$$

This expression involves the dry deposition/accumulation factor $\left(K_{1}\right)$, the life-time factor for dust $\left(K_{2}{ }^{\text {Dust }}\right)$, the source factor for dust $\left(K_{3}{ }^{\text {Dust }}\right.$ ) and the residual $R_{3}{ }^{\text {Dust }}$. For EDC dust and calcium and Vostok dust, $\beta$ is $0.0157 ; \delta D_{\mathrm{H}}$ is the mean deuterium value for the Holocene; $\left(t_{-} t^{\text {Dust }} / \tau_{\mathrm{H}}{ }^{\text {Dust }}\right)$ is $4 ; \eta$ is $0.7 ; \gamma$ is $0.07 \pm 0.01$ for EDC and Vostok; $S_{1}$ and $S_{2}$ are defined as

$S_{1}=0$ for $\delta D \geq \delta D_{1}$ and $S_{1}=1$ for $\delta D<\delta D_{1} ; \delta D_{1}=-405$ and $-445 \%$ for EDC and Vostok, respectively.

$S_{2}=0$ for $\delta D \geq \delta D_{2}$ and $S_{2}=1$ for $\delta D<\delta D_{2} ; \delta D_{2}=-425$ and $-465 \%$ for EDC and Vostok, respectively.

Amongst the six parameters in eq. (9), four $\left(\delta D_{1}, \delta D_{2}, \eta\right.$, $\gamma$ ) remain adjustable while $\beta$ and $t_{-} t^{\text {Dust }} / \tau_{\mathrm{H}}{ }^{\text {Dust }}$ are in somehow constrained by glaciological models and aerosol observations, respectively. For maximum glacial conditions, the dry deposition/accumulation factor is $\sim 2$, the life-time factor is $\sim 5$ and the apparent source factor is $\sim 3-4$, corresponding to an overall increase of $\sim 30-40$ in concentrations with respect to Holocene conditions. At this step, the dust residuals $\left(R_{3}{ }^{\text {Dust }}\right)$ of the two sites are no longer correlated to the isotope values, and the values are not too far from a Gaussian distribution $N(\sim 0, \sigma)$ with $\sigma \sim 0.5-0.7$ (i.e. $\sigma^{2} \sim 0.23-0.51$, Table 1). For EDC and Vostok sites, the model can explain $70-80 \%$ of the signal variance and reproduces the dust concentration to within a factor of $2\left(\sigma_{\mathrm{g}}\right.$ varying from 1.62 to 2.04 , Table 1 ) for about $68 \%$ of the cases (assuming a normal distribution). However, some of them are still not random (see Figs 5A and B for EDC) and in the time domain both sites contain a remaining variability we will associate with orbital frequencies (see next section and the subsequent discussion). For the purpose of this paper, we will limit variance reduction to this step.

\subsection{Sodium}

Assuming that dry deposition applies for sodium at EDC and Vostok sites, the dry deposition/ accumulation factor from the model $\left(k_{1}\right)$ is identical to that for dust. The residual $R_{1}{ }^{\text {Sodium }}$ still has a monotonic (linear) correlation with the isotope content (Figs $3 \mathrm{C}_{1}$ and $\mathrm{E}_{1}$ ), and as opposed to the dust proxy, no threshold is needed. We therefore applied the life-time factor for marine aerosol $\left(k_{2}{ }^{\text {Sodium }}\right)$ over the full range of isotope content values. As for dust, the parameter ' $\eta$ ' is adjusted and the value of $\sim 0.7$ for EDC and Vostok sites satisfy the conditions for a corrected sodium flux (atmospheric load) equivalent to the interglacial values, at the most. The mean life-time factor accounts for a 2.5-fold increase for LGM sodium concentrations.

For both EDC and Vostok data, the variance of the sodium residual $\left(R_{2}{ }^{\text {Sodium }}\right)$ is significantly lower $\left(\sigma_{\mathrm{g}}\right.$ is 1.20 and 1.41 , respectively) and apparently, the combined effect of the accumulation factor and the life-time factor already compensate for most of the sodium concentration variance with respect to the isotope content (Figs $3 \mathrm{C}_{2}$ and $\mathrm{E}_{2}$ ). The sodium concentration can be expressed by the equation (sum of $K_{1}$ and $K_{2}$ Sodium factors and residual $R_{2}$ Sodium)

$$
\begin{aligned}
& \operatorname{Ln}\left(C / C_{H}\right)=-\beta\left(\delta D-\delta D_{\mathrm{H}}\right)+t t^{\text {Sodium }} / \tau_{\mathrm{H}}^{\text {Sodium }} \\
& \quad \times\left\{1-\exp \left[\eta \beta\left(\delta D-\delta D_{\mathrm{H}}\right)\right]\right\}+R_{2}^{\text {Sodium }}
\end{aligned}
$$

where $t_{-} t^{\text {Sodium }} / \tau_{\mathrm{H}}$ Sodium is 2 , the other factors are the same as for the dust model.

Three parameters drive eq. (10) and if $\beta$ and $t_{-} t^{\text {Sodium }} / \tau_{\mathrm{H}}$ Sodium are independently constrained; only $\eta$ is an adjustable parameter. The model reproduces the observed sodium concentrations within a factor of $\sim 1.3\left(\sigma_{\mathrm{g}} \sim 1.20\right.$ to 1.41 , Table 1$)$ for about $68 \%$ of the cases (case of a normal distribution). $R_{2}{ }^{\text {Sodium }}$ values are close to a Gaussian distribution $N(\sim 0, \sigma)$ with $\sigma \sim$ $0.17-0.40$ (i.e. $\sigma^{2} \sim 0.03-0.12$, Table 1 ). Similarly to the dust residual, the sodium residual $\left(R_{2}{ }^{\text {Sodium }}\right)$ is no longer correlated to the isotope values but appears to be non-random with respect to time. Undulations at orbital frequency are present (see the discussion below).

\subsection{Statistical test}

Starting from datasets corresponding to Holocene climate (hereafter initial reference values) we have introduced the different climatic factors and variable parameters. The dry deposition/accumulation factor was introduced first to compensate the overall concentrations values. The resulting dataset become closer in term of mean and standard deviation to that of the initial reference values. Then the life-time factor (for sodium and dust) and the source factor (for dust only) were applied until most of the compensated concentration values become closer (leastsquare fitting) to the initial reference values. The frequency distributions of residuals $\left(R_{0}, R_{1}, R_{2}\right.$ and $\left.R_{3}\right)$ for sodium and dust display very different patterns (Fig. 4 right-hand panels) and 

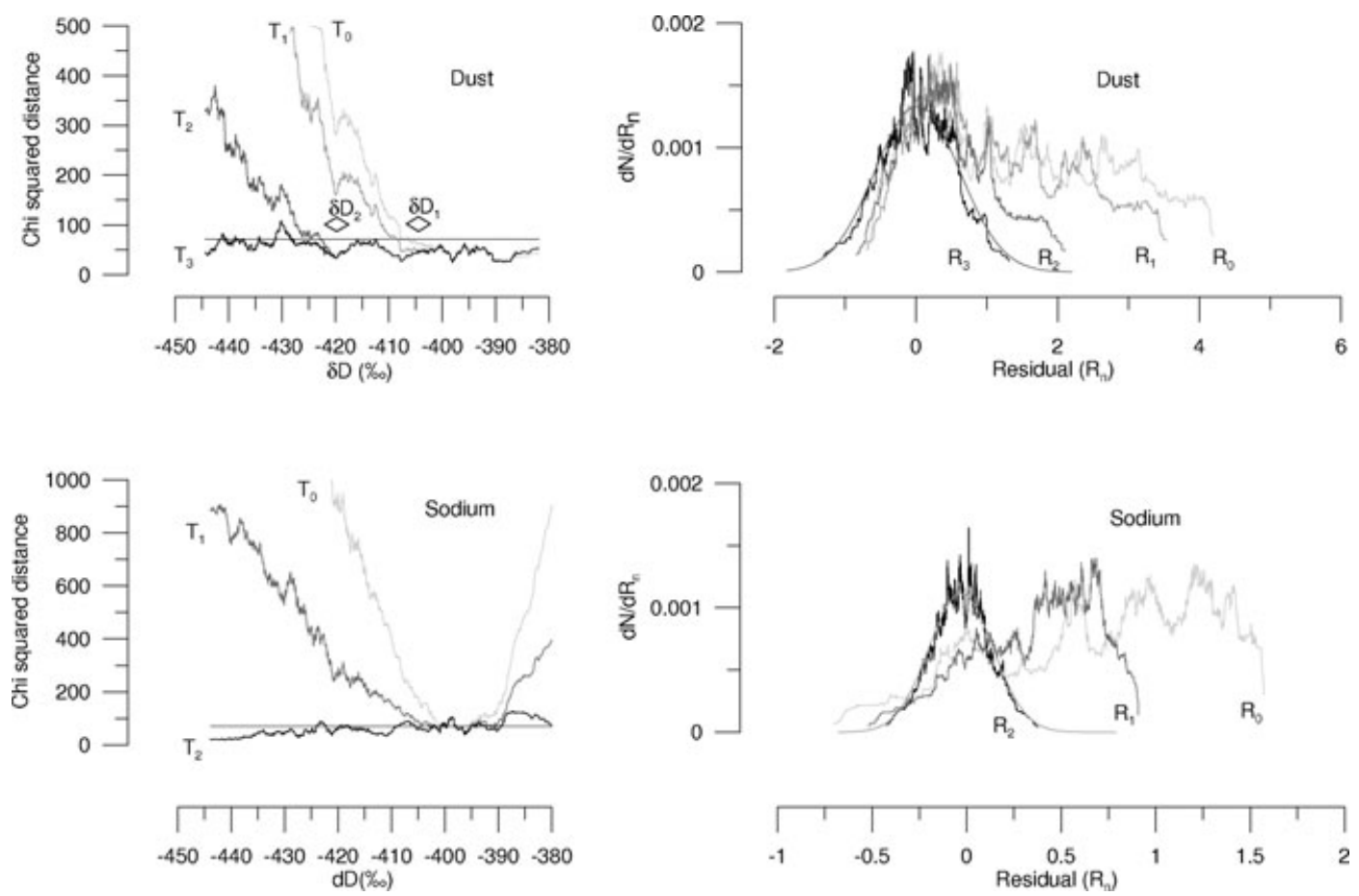

Fig. 4. Chi-square distances $\left(T_{n}\right)$ for EDC dust and sodium as calculated from 50 successive values of residuals $R_{n}$ versus deuterium content (left-hand panels) and frequency distributions $\left(\mathrm{d} N / \mathrm{d} R_{n}\right)$ of residual values (right-hand panels). The chi-squared test value $(\sim 70)$ is indicated by the horizontal line. $\delta D_{1}$ and $\delta D_{2}$ are the deuterium thresholds for the dust. Gaussian distributions $N(0.02,0.60)$ for dust and $N(-0.03,0.18)$ for sodium, respectively, are also shown.

allow appreciating the influence of the different factors. The frequency distribution of the final residuals for sodium $\left(R_{2}{ }^{\text {Sodium }}\right)$ and dust $\left(R_{3}{ }^{\text {Dust }}\right)$, respectively become very close to the initial reference values for both the mean $(\sim$ zero) and the standard deviation $(S D)$ and close to a Gaussian.

A chi-squared distance test was applied on the EDC dust and sodium series, considering these latter as the best available datasets. We build a Gaussian distribution for reference values based on the $S D$ of $R_{3}{ }^{\text {dust }}$ and $R_{2}{ }^{\text {sodium }}$ (deduced from more than $\sim 1000$ values) that we use as our null hypothesis. The sodium and dust relationship with climate could be evaluated through the evolution of the residuals values (relative to $S D$ ) with respect to $\delta D$ and as the different climatic factors are introduced. To this end, we consider the chi-square quantity $T_{n, i}$ set to be the squared sum of 50 successive residual values of $R_{n, j}$ divided by $S D$, that could be then tested against a chi-square distribution of a noise. $T_{n, i}$ is written as

$T_{n, i}=\sum_{j=i}^{j=i+50}\left(R_{n, j} / S D\right)^{2}$.

Residuals $\left(R_{n, j}\right)$ are first ranked with respect to deuterium $\left(\delta D_{j}\right.$, increasing difference with Holocene or interglacial values) and instead bins, the window of the 50 successive values is moved for scanning over all $\delta D_{j}$ values. On Fig. 4 (left-hand panels) are shown $T_{0}, T_{1}, T_{2}$ and $T_{3}$ values corresponding, respectively, $R_{0}$,
$R_{1}, R_{2}$ and $R_{3}$ residuals and plotted against $\delta D_{i}$ (i.e. the moving mean over 50 successive deuterium values). The highest values, up to 4000 and 1000 for dust and sodium, respectively, is represented by $T_{0}$ for most extreme $\delta D$ (glacial climate) and initial concentration datasets $\left(R_{0}\right)$. The chi-squared test is used and for $T_{n}$ value lower than $\sim 70$, the $S D$ of residuals is considered as the $S D$ of our Gaussian reference distribution and null hypothesis accepted $(P<0.02$, d.o.f. $\sim 50)$.

Most of the $T_{2}$ values for sodium (Fig. 4 lower left-hand panel) satisfy the null hypothesis $\left(T_{2}\right.$ lower than 70$)$, except a few data points corresponding to the highest $\delta D$ (i.e. interglacial climate). These values correspond to very low sodium concentrations; they may be outliers, and no attempt was made to improve the fit. The two factors we introduced (dry deposition/accumulation factor and life-time factor) allow scoring satisfactorily the null hypothesis. The two factors correspond to two physical processes; none of these factors taken alone could explain the whole variability of the signal.

For the dust, (Fig. 4 upper left-hand panel) both $T_{0}$ (concentration) and $T_{1}$ (flux) increase steadily and the null hypothesis is rejected for $\delta D$ values below $\sim-410 \%$, justifying the introduction of a complementary climatic factor beyond a deuterium threshold. Once the life-time factor and the first threshold $\left(\delta D_{1}\right)$ are applied, $\mathrm{T}_{2}$ better scores for the null hypothesis, except for $\delta D$ values lower than $\sim-420 \%$. A third climatic factor associated to dust source and a second threshold $\left(\delta D_{2}\right)$ allow 
$T_{3}$ scoring efficiently the null hypothesis. These three factors (dry deposition/accumulation, life-time, source) correspond to physical processes and they all seem necessary, as none of them, taken alone, could reasonably explain the whole signal. The two thresholds seem also necessary while their climate meaning (e.g. threshold in atmospheric mode or coupling) will be discussed afterwards.

Our approach requires a total of six and three parameters for reducing variance of dust and sodium datasets, respectively (more than 1000 values), while an excess of parameters may raise question about possible overdetermination. Alternative fittings of dust and sodium concentrations with respect to $\delta D$ involving a reduced number of parameters may be proposed. The logarithm of dust (sodium) concentrations could be satisfactorily fitted versus $\delta D$ by a polynomial (linear) equation involving three (one) parameters, but without clear physical meaning. Our choice was guided by factors linked to the atmospheric cycle and properties of aerosols. The search for positive climatic factors applied in multiplicative way avoids negative concentrations and justify the use of logarithm. In addition, the distributions of the residuals change significantly as the different factors are applied (Fig. 4 right-hand panels). Such qualitative considerations may be used to justify the need of all climatic factors and associated thresholds and fitting parameters, we used. The risk for over-determination is therefore considered to be low.

Sensitivity tests indicate some interdependence between fitting parameters $(\eta$ and $\gamma$ ), but only within narrow limits. Adopting for $t_{-} t^{\text {Dust }} / \tau$ Dust a value of $\sim 4$, considering the EDC coulter counter dataset, best representative of the dust signal, the $\delta D_{1}$ and $\delta D_{2}$ thresholds may change by $\pm 5 \%$ at the most (see Fig. 4 upper left-hand panel) while values for fitting parameters vary between 0.5 and 0.8 for $\eta$ and between 0.06 and 0.10 for $\gamma$. When applied to a new set of 5164 dust values from laser system (Lambert et al., 2008), our model fully satisfies the null hypothesis by using $-405 \%,-425 \%, 0.67,0.08$ for $\delta D_{1}, \delta D_{2}, \eta$ and $\gamma$, respectively (not shown) and well consistent with above estimates.

\section{Discussion and climatic implications}

\subsection{Model results and constraints on parameters}

4.1.1. Model outputs. A large part (70-90\%) of the variance of dust and sodium in EDC and Vostok ice cores can be explained by either three climatic factors and two thresholds (for dust) or only two climatic factors (for sodium). All factors are linked to temperature (stable isotope composition of ice). The dust and sodium residuals $\left(R_{3}{ }^{\text {dust }}\right.$ and $\left.R_{2}{ }^{\text {sodium }}\right)$ appear close to a Gaussian but still not random for which the available data resolution already makes it possible to decipher undulations and orbital structures of interest (Fig. 5).
The output from model includes a mean troposphere temperature in the atmospheric pathway over the Southern Ocean, inferred from the fitting parameter $(\eta)$ in life-time factor $\left(k_{2}{ }^{\text {dust }}\right.$ and $\left.k_{2}{ }^{\text {sodium }}\right)$. For dust and sodium, $\eta$ is $\sim 0.7$ from which we deduce a high-troposphere temperature over the Southern Ocean $\sim 3.5-5{ }^{\circ} \mathrm{C}$ cooler for LGM and glacial periods than for Holocene climate (i.e. 0.7 times the temperature change at the top of the inversion layer over the Antarctic plateau). Interestingly, from deuterium excess analysis of ice, Stenni et al. (2002) obtain similar value for temperature change over the oceanic source for the Antarctic precipitation. Our $3.5-5{ }^{\circ} \mathrm{C}$ value is also consistent with several other studies suggesting $\sim 4{ }^{\circ} \mathrm{C}$ cooling during LGM in Southern Atlantic (Brathauer and Abelmann, 1999; Lamy et al., 2004), in the subtropics over South America (Stute et al., 1995, Lea et al., 2003) as well as in the sub-Antarctic region for the previous glacial periods (Martinez-Garcia et al., 2008 and personal communication). The similarity between temperature change at ocean surface and within the high troposphere is likely, assuming no significant change in the atmospheric lapse rate over the Southern Ocean.

The output of the model also includes a dust source factor inferred from $k_{3}{ }^{\text {Dust }}$. This climatic factor is associated with the midlatitude atmospheric dust load or 'Apparent Source Efficiency Factor' (ASEF) and is simply calculated (eq. 8). ASEF therefore inherits the isotope variability beyond the second threshold $\left(\delta D_{2}\right)$. For glacial periods ASEF is approximately two to four times bigger than the reference value for interglacial periods (Fig. 5 for EDC). By comparison, over continental areas and at mid-latitudes, marine and terrestrial records suggest LGM dust fallout approximately three to fivetimes bigger than present (DIRTMAP inventory, Kohfeld and Harrison, 2001). In this respect, the ASEF we deduce is of same order of magnitude. ASEF is also consistent with other dust fallout from south Atlantic marine records such as: the approximately five-fold increase of iron deposition originating in Patagonia (Kumar et al., 1995); the $\sim 4$-fold increase of dust deposition in the south Atlantic and downwind of the South American source (Martinez-Garcia et al., 2008; and personal communication). For other dust sources from South America, Winckler et al. (2008), produced dust records from Equatorial Pacific marine series which mimic the EPICA dust record over four climatic cycles inferring a glacial-interglacial source change of about 2-2.5.

Both temperature and dust source outputs from our model fall within independent estimates. Aside from the assumption of dry deposition over Antarctica (e.g. Wolff et al., 2006), our approach was based on the key assumption of a close dependence of climate on aerosol e-folding time, the latter likely falling within the assumption that aerosol pathways operate at high altitudes within the cold troposphere. We now discuss constraints on variables influencing the model results: i.e. the life-time factor and the fitting parameters $\eta$ and $\gamma$. 

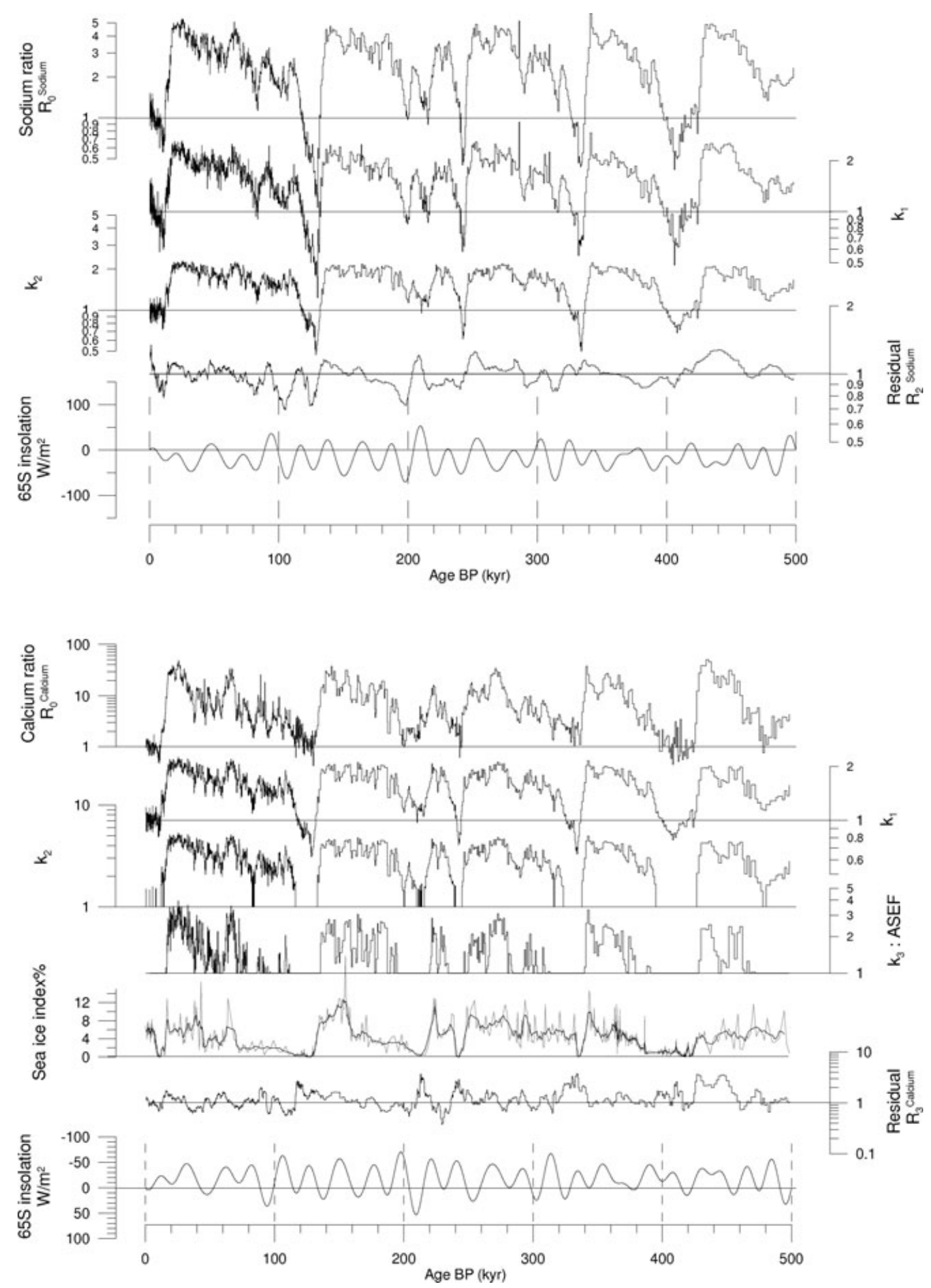

Fig. 5. EPICA Dome C records of dust and sodium concentration over the last $500 \mathrm{kyr}$ and the contribution of the different factors as deduced from the model, along with sea ice index and $65^{\circ} \mathrm{S}$ austral summer insolation. Upper panel: EPICA Dome $\mathrm{C}$ sodium record. From top to bottom: Sodium concentration $\left(R_{0}\right.$ Sodium $)$, dry deposition/accumulation factor $\left(k_{1}\right)$, life-time factor $\left(k_{2}\right)$, sodium residual $\left(R_{2}{ }^{\text {Sodium }}\right)$ and $65^{\circ} \mathrm{S}$ austral summer insolation. Lower panel: EPICA Dome $C$ record of calcium. From top to bottom: calcium concentrations $\left(R_{0}{ }^{\text {Calcium }}\right)$, dry deposition/accumulation factor $\left(k_{1}\right)$, life-time factor $\left(k_{2}\right)$, source factor (ASEF, $k_{3}$ ), winter sea ice extent index for South Atlantic (\%) at ODP site 1094 (Kunz-Pirrung and Gersonde, in prep, courtesy of $R$. Gersonde); calcium residual $\left(R_{3}\right.$ Calcium) and $65^{\circ} \mathrm{S}$ austral summer insolation (reversed axis). 
4.1.2. Life-time factor. During LGM and previous glacial periods, the life-time factor and atmospheric dust load increases up to a five-folds with respect to interglacial values. The life-time factor from our model predominates most of the other climatic factors. Compared to previous interpretations (e.g. Wolff et al., 2006; Fisher et al., 2007a), the life-time factor we have introduced is more significant, due to the e-folding time and long mean transit time for dust that we have used.

We assume that cleansing during transport may have a considerable effect on the glacial aerosol inputs (Hansson, 1995, 1996; Yung et al., 1996). A link with the amount of precipitation and the atmospheric vapour content is generally parametrized in model (Genthon, 1992, see Appendix A1). With troposphere temperatures as cold as in the inversion layer over the Antarctic plateau (e.g. $-40{ }^{\circ} \mathrm{C}$ ), with a $4{ }^{\circ} \mathrm{C}$ cooling, a factor of about two in atmospheric vapour may be inferred, as obtained for the snow accumulation rate over Antarctica (Schwander et al., 2001), and therefore within the e-folding time for glacial periods (i.e. from one week up to 2 weeks). This e-folding time value is indeed consistent with estimates from AGCMs (Mahowald et al., 1999; Werner et al., 2002), but for small-size dustbins, less affected by gravitational settling.

A value of one month for mean dust transit time would also appear to be questionable with respect to the value of about 5 d usually used (e.g. Reijmer et al., 2002). However this would assume that the advection of the continental dust to the polar plateau is more or less associated with the frontal and cyclonic system around Antarctica, which holds better for the marine aerosol emitted from the surrounding Southern Ocean. As stated before, our ice cores samples are representative of a mean climatology over several years, and the corresponding mean transit time for the dust hardly corresponds to such a rapid transfer time. Instead, it may better correspond to a transit time of sodium once weighted to take into account the probability of occurrence.

Krinner and Genthon (2003) obtained tracer ages of about one week for the transit time of radioactive-like tracers with the LMDZ AGCM model. The authors, however, pointed out difficulties in estimating air mass ages which are likely older. Indeed, the mixing of the air parcel with new young air systematically shifts the air mass age toward younger values leading to a mean tracer age close to the chosen e-folding time. Such a simulation likely better represents the transit of aerosol to Antarctica through the low troposphere, while the representation of vertical mixing up to the high troposphere may be over estimated.

The dust size distribution change is also an indicator of transit time; an example is provided by meteorological dust outbreaks transporting Asian dust to North America. One week after emission, the volume size distribution displays a mode around $4 \mu \mathrm{m}$ while particles as large as $10 \mu \mathrm{m}$ are present (e.g. Zdanowicz et al., 2006). By comparison, Antarctic dust has a modal diameter around $2 \mu \mathrm{m}$ while particles larger than $5 \mu \mathrm{m}$ are very scarce (except from proximal volcanic events), implying a systematically long (i.e. more than one week) atmospheric journey allowing large particles to settle.

Rapid continental air mass pathways do exist as shown by sudden radioactivity spikes of ${ }^{222} \mathrm{Rn}$ (e.g. radonic storm, Lambert et al., 1970, Maenhaut et al., 1979) inherited from the continents. This has been observed in coastal areas of Antarctica, but not documented yet at inland station. In this respect, mean ${ }^{222} \mathrm{Rn}$ concentrations serve as a robust constraint leading to a mean transit time in our simplified approach as long as 3-4 weeks.

4.1.3. Constraints on fitting parameters $(\eta$ and $\gamma)$. The fitting parameter $(\eta)$ is introduced in the life-time factor $\left(k_{2}\right)$ for dust and sodium. When applied, the corresponding residual for dust and sodium flux decreases. However, with $\eta=1$ the fluxes are lower than those of interglacial periods, a result which rises issues. In fact, during these warm periods, the hydrological cycle is likely enhanced, minimizing the probability of aerosol reaching polar areas. The effect on dust should be more significant as continental aridity and source emissions are likely reduced at the same time. Our assumption is that the lowest atmospheric aerosol loads over Antarctica occur, on average, only during interglacial periods.

The behaviour of dust concentration with respect to climate could be understood within the concept of a coupling by step of the polar climate with lower latitudes as the climate is cooling (Lambert et al., 2008). This leads us to consider a change in the e-folding time (and in life-time factor) below a temperature threshold that we associate with a first coincident cooling of the Antarctic troposphere and both the upper troposphere and ocean around Antarctica. Then, below a second temperature threshold, we involve the source and deflation of southern South America once cooling is already important. The mean values of dust and sodium flux for interglacial periods therefore provide constraints on ' $\eta$ ' and ' $\gamma$ ' values. The parameter ' $\eta$ ' value is therefore adjusted to satisfy the conditions to lower the dust or sodium flux to become equivalent to that observed for the interglacial period, at the most. The same assumption is used to deduce the parameter ' $\gamma$ ' and dust source change.

\subsection{Climatic interpretation of dust parameters}

We introduced two isotope thresholds to take into account the behaviour of the dust with climate. The EDC and Vostok climate records are very similar over the common period of the last four climatic cycles. On average, the deuterium profiles of the two sites differ by about $40 \%$ as reflected by the mean Holocene value of -396 and $-440 \%$ for EDC and Vostok, respectively. The two dust records are also similar; the isotopic thresholds $\left(\delta D_{1}\right.$ and $\left.\delta D_{2}\right)$ are separated by a similar $20 \%$ isotope content difference (i.e. -405 and $-425 \%$ for EDC and -445 and $-465 \%$ for Vostok, respectively). The consistency of the thresholds from 
two different sites suggests a change in the climate system or a switch into new climate modes.

4.2.1. Threshold 1. Threshold $1\left(\delta D_{1}\right)$ was defined by the increase of the dust flux as Antarctic temperature becomes cooler ( $\delta D_{1}$ values are about $10 \%$ lower than the mean Holocene value and the Antarctic troposphere/top of inversion layer temperature is about $1{ }^{\circ} \mathrm{C}$ cooler). Above $\delta D_{1}$ and for interglacial climates, the dust flux to Antarctica is almost constant. Below $\delta D_{1}$, we attributed the dust flux increase to the e-folding time change and finally to the atmospheric temperature along the dust pathway.

An alternative scenario would be the possible contribution from the source at the same time as a moderate life-time factor (e.g. Wolff et al., 2006; Fischer et al., 2007a). In other words, environmental conditions over the source regions (e.g. Patagonia) might have already changed in parallel to modest changes of the Antarctic climate. However, such a permanent link does not seem to be supported by the climate record for the last deglaciation and the Antarctic Cold Reversal (ACR) period in Antarctica has little corresponding evidence from Southern South America (Delmonte et al., 2002). Involvement of a life-time factor before the source factor provides a consistent approach as far as the hydrological cycle is concerned and that polar regions and high troposphere are more sensitive to cooling than mid-latitudes.

Threshold 1 could be therefore interpreted as a switch to a climate mode involving a temperature coupling between the high level of the troposphere above the Southern Ocean and the Antarctic troposphere. In our model, this is understood as a coincident and proportional temperature drop over the two regions. Conversely, above the temperature threshold, the two troposphere temperatures may vary independently. As an implication for ice core records, the absence of correlation between the dust and the isotope records could represent a criterion to characterize the onset and the conclusion of each interglacial period.

4.2.2. Threshold 2. The second threshold $\left(\delta D_{2}\right)$ was defined from the additional increase in the dust concentration as climate changed to glacial conditions. The isotope content is about $30 \%$ lower than the Holocene value $\left(\sim-4{ }^{\circ} \mathrm{C}\right.$ for Antarctic troposphere) and half the lowest value of about $70 \%$ lower $\left(\sim-8{ }^{\circ} \mathrm{C}\right)$. This also corresponds to well-established glacial climate conditions, significant amounts of continental ice and sea level lowering. Sea level lowering causes the Argentinean continental shelf to emerge, moving the shore-line seaward by hundreds of kilometres. The emerged continental shelf would not appear to be a significant dust source for Antarctica (Basile et al., 1997; Wolff et al., 2006; Gaiero, 2007), but during sea level low stands, the climate of southern South America, the main glacial dust supplier (Delmonte et al., 2004b), was likely more continental. The development of the ice cap in Patagonia, the extension of sea ice in the south Atlantic sector along with northward shift of the polar front and westerly belt, added constraints by reinforcing the aeolian deflation. For example, the end of the steady dust decrease during the last climatic transition
( $\sim 14.6 \mathrm{kyr}$ BP) was associated with the re-onset of NADW formation and the retreat of glacial sea ice in the south Atlantic (Jouzel et al., 1995).

The extension of the cold climate over the Southern Ocean along with the extension of sea ice and the shift of the westerlies together impose dry continental conditions over southern South America, which was subject to aridity and severe aeolian deflation. Moreover, the presence of an ice cap over Patagonia associated with the extension of proglacial areas and with periglacial processes enhanced the production of mobilizable fine sediments. In this respect, our dust source factor $\left(k_{3}{ }^{\text {Dust }}\right)$ may be compared by some means to the index of sea ice extent in the south Atlantic (Fig. 5 lower panel) deduced independently from marine sediment cores (Kunz-Pirrung and Gersonde, personal communication, 2009; Gersonde, personal communication, 2008). In fact, as our parameter is defined below $\delta D_{2}$, the marine sea ice indicator may be sensitive to sea ice extent only once the sea ice edge reaches given latitude or significantly influences the water surfaces. We believe that sea ice area should be continuously associated with the Antarctic temperature.

Finally, threshold 2, related to dust behaviour, would appear to correspond to Antarctic and Southern Ocean temperature under full glacial conditions. The onset and conclusion of extreme climate conditions is provided by $\delta D_{2}(-425$ and $-465 \%$ for EDC and Vostok, respectively). The climate coupling was not limited to the sub-Antarctic region, but extended globally. Indeed, the short term Dansgaard/Oeschger climate events occurring under such conditions have influenced most of the northern hemisphere and entire Atlantic Ocean (Stocker et al., 2003). They are observed in Antarctic ice core records (EPICA Community Members, 2006; Fischer et al., 2007b, Jouzel et al., 2007) as well as in south Pacific marine records (e.g. Pahnke and Zahn, 2005). The global ocean regulates the atmospheric $\mathrm{CO}_{2}$, and the lowest values likely correspond to a probable stratified ocean (e.g. Franois et al., 1997) or a glacial mode.

The involvement of the dust source reflects the atmosphereocean-sea-ice-continent couplings and threshold 2 in Antarctic ice cores could characterize the reinforcement of the existing coupling and boundary conditions for climate modes under full glacial conditions.

\subsection{Climate implications of sodium}

4.3.1. Model results. For sodium, glacial enhancement could be simulated to within a factor of $\sim 1.2$, with accumulation accounting for a factor of 2 increase and aerosol life-time accounting for a factor of 2.5 increase. For marine aerosol, it has been suggested that the increase in flux during glacial periods may reflect the contribution from sea ice on which frost flowers may form and become a potential source for sodium through re-emission (Rankin et al., 2002). The wider the sea ice surface around Antarctica, the larger the sea salt source (Wolff et al., 2003), that appear coincident with seasonal late winter-early spring 
maximum in sodium concentration measured in air (Cunningham and Zoller, 1981) and in snow (Legrand and Kirchner, 1988).

The frost flower scenario should induce chemistry changes in aerosol composition (sulphate depletion with respect to sodium) as observed in coastal sites. Conversely, available air and snow chemistry data for inland sites are controversial, as there are evidences supporting (Wolff et al., 2006) and others challenging (Hara et al., 2004) such a link or suggesting a negligible contribution (less than 5\%, Curran et al., 2008). Furthermore, the question may be posed as to how the source of sea ice salt remains uncovered by snow precipitation throughout the winter, as well as to how efficient is its uplifting to an altitude of $4 \mathrm{~km}$ while convection over sea ice is limited. Noone and Simmonds (2002) consider that much of the sea-ice zone is precluded from air masses having sufficient kinetic energy to reach altitudes above $2000 \mathrm{~m}$ that may not be sufficient to supply inland sites. On the other hand, the more remote open ocean becomes the dominant source of air masses. Finally, the permanent cyclonic activity associated with the polar front and at the edge of the sea ice appears to be a more efficient source for sea spray and better candidate as sodium source.

Sea ice extent around Antarctica is closely linked to the coastal Antarctic temperature so that glacial-interglacial changes are more or less proportional to temperature changes in the interior of Antarctica. Based on our approach, the sea ice extent signal remains convoluted within the isotope signal and it may not be possible to disentangle it from sodium fluxes alone. If sea ice extent is not strictly linked to isotope content, our model suggests a contribution representing less than $10 \%$ of the total sodium variance. With such considerations, our model would suggest a constant atmospheric load of sodium over the source and therefore independent of the climate changes. If correct, our model raises the question as to why the increased distance by (greater) sea ice extent is not seen on the sodium flux.

4.3.2. Sea ice extent and sodium flux uncorrelated?. Indeed, a longer travel time for marine aerosol ( $\left.t_{-} t^{\text {Sodium }}\right)$ leading to a higher decrease of the air concentration, may be compensated by a reduced atmospheric washout (longer e-folding time) because a slightly cooler low-troposphere temperature. A sensitivity test

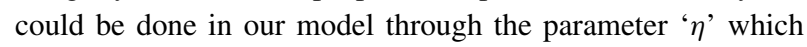
reduces or amplifies with respect to Antarctic temperature, the overall temperature along the sodium pathway. With respect to eq. (10) and the expression of sodium concentration changes involving the accumulation factor $\left(k_{1}\right)$ and the life-time factor $\left(k_{2}{ }^{\text {Sodium }}\right)$, a constant source factor $\left(k_{3}{ }^{\text {Sodium }}\right)$ could be added

$k_{3}^{\text {Sodium }} \sim \exp \left(-t \_t^{\text {Sodium }} / \tau^{\text {Sodium }}\right)=$ constant

with $t_{-} t^{\prime \text { Sodium }}$ holding for transit time over the sea ice and $\tau$ the corresponding e-folding time. Using the derivative we obtain

$\delta t_{-} t^{\text {Sodium }} / t_{-} t^{\text {Sodium }}=-\delta \tau / \tau^{\text {Sodium }}$ and then using the expression of the e-folding time of eq. (7), it comes

$\delta \eta=-\delta t_{-} t^{\prime \text { Sodium }} / t_{-} t^{\prime \text { Sodium }} \cdot[\beta(\delta D-\delta D H)]^{-1}$.

For example, assuming a $30 \%$ increase in the distance from the edge of the sea ice to the site and in the transit time $\left(\delta t_{-} t^{\text {,Sodium }} / t_{-} t^{\text {,Sodium }}\right)$ for glacial conditions, $\delta \eta$ would be $\sim 0.3$, giving a corresponding value of $\eta$ close to $\sim 1$ instead 0.7 . With $\eta \sim 1$, the new estimate for temperature change for the low-troposphere around Antarctica would be -5 to $-7{ }^{\circ} \mathrm{C}$ (instead $-3.5-5{ }^{\circ} \mathrm{C}$ ) and similar to that at inversion level over the Antarctic plateau. This seems consistent with a larger temperature drop as deduced from the isotope content of ice cores for coastal areas (Jouzel et al., 1989) while ice sheet altitude changes also contribute.

\subsection{Residual signals}

4.4.1. Spectral properties in the time domain. The dust and sea salt residuals from EDC are shown in Fig. 5 for the last $450 \mathrm{kyr}$. Over the time domain, dust and sodium residuals contain energy in the precessional bands ( $2319 \mathrm{kyr}$ ) of orbital periodicity and to a lesser degree in the obliquity band (40 kyr) (see Figs 6A and C). Cross-correlation and phase analysis indicate that sea salt is out of phase with respect to dust (leading or lagging by about $3 \mathrm{rad}$, or $180^{\circ}$ ) over most frequencies (Fig. 6D), a point which deserves special attention.

Residuals are significantly correlated with $65^{\circ} \mathrm{S}$ insolation (Fig. 6C for dust): sea salt residual is consistent with the maximum (i.e. summer) austral insolation (Fig. 6B) while dust residual is opposite and therefore minimum. Identical conclusions for sodium and dust residuals can be deduced from Vostok data analysis, as will be seen later on. It is worth notifying that the $100 \mathrm{kyr}$ oscillations which dominate the climate and temperature records are considerably reduced. While initial variations of sea salt and dust concentration display similar behaviour with respect to climate (Fig. 1), the opposite behaviour of residuals (Fig. 6D) suggests that the parametrization and successive corrections using the different climatic factors, all considered being a function of isotope content values, have not spoiled the properties of the residuals. Moreover, sensitivity tests were performed by introducing a periodic $(20 \mathrm{kyr})$ signal with variable amplitude into the isotope records. As long as the amplitude of the perturbation signal does not exceed $10 \%$ o ( $~ 15 \%$ of the isotope amplitude signal) the original precession component of each residual is still decipherable. The robustness of the signal increases when residuals (normalized units) are appropriately combined (i.e. sodium minus dust or calcium) suggesting that the periodicities are likely not calculation artefacts.

The presence of the precession signal in five different residual records (two sodium, two dust and one calcium) available for two different sites in Antarctica provide additional support for a true properties of the aerosol records, instead a bias from 

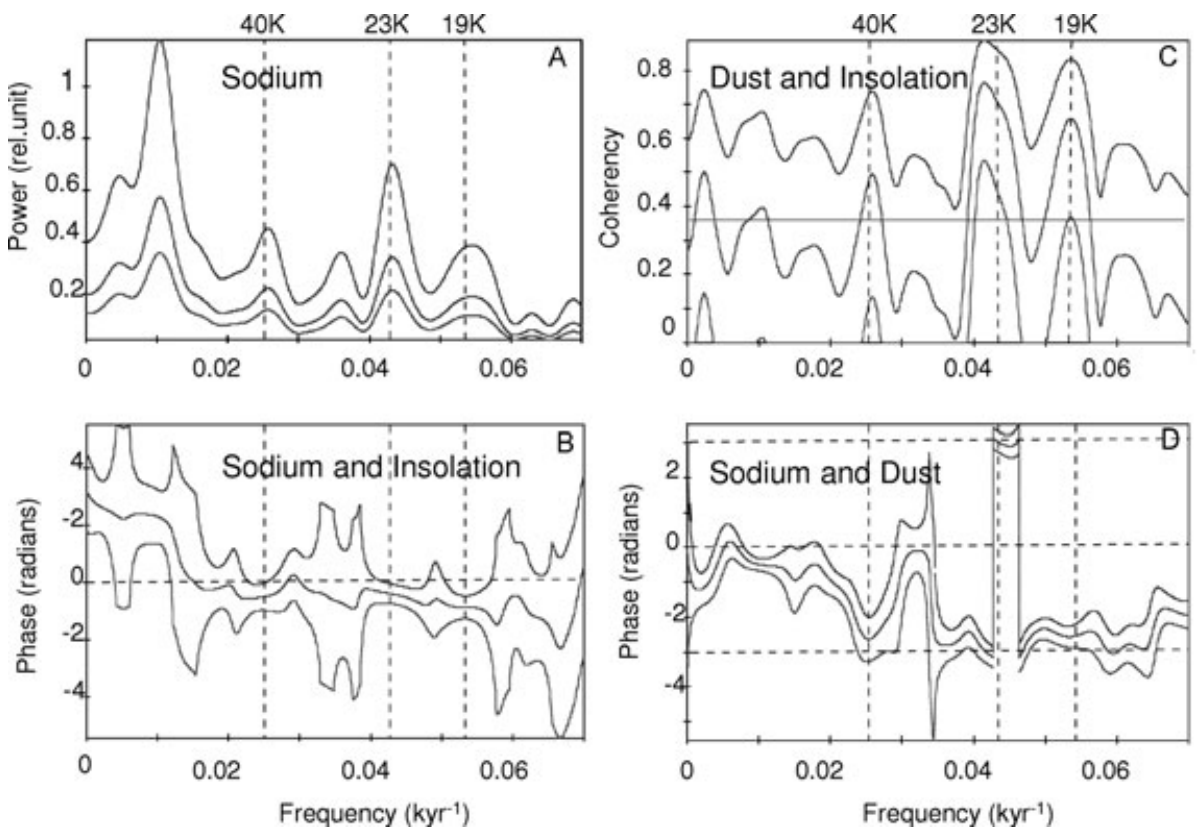

Fig. 6. Power spectra and cross-correlations for sodium, dust and insolation. Panel A: sodium residual power spectrum. Panel B: sodium residual and $65^{\circ} \mathrm{S}$ austral summer (December 21) insolation cross correlation: phase spectrum. Panel C: dust and $65^{\circ} \mathrm{S}$ austral summer insolation cross-correlation: consistency spectrum. The consistency factor is considered to be significant for values $>0.38$ (horizontal line). Panel D: sodium and dust cross correlation: phase (radians) spectrum. The value of +3 or -3 radians, almost continuous, indicates that the signals are in opposite phase for orbital periodicities. Spectra are calculated using the Blackman Tukey algorithm and Analyseries software (Paillard et al., 1996). Upper and lower spectra provide the confidence interval.

calculations. Moreover, the precession signal is also present in the non-sea salt sulphate (nss-SO ${ }_{4}$ ) flux from EDC (see Fig. 7 and Appendix Section A2) while data reduction is only limited to the first (dry deposition/accumulation) factor (Fig. $3 \mathrm{~F}_{1}$ ). As a result of the successive correlations, the variability of residuals likely results from phenomena of second order, which are not linked to temperature, but likely to source and/or to transit.

4.4.2. A link between continental and marine sources with precession?. At the South Pole, sea salt concentration peaks at the end of winter, while dust and most of the impurities peak in summer (Legrand and Kirchner, 1988; Tuncel et al., 1989). The lagged (almost opposite) seasonality of sodium and dust is also reproduced on an orbital time scale and preserved in residuals dominated by a precession signal. An underlying physical link is therefore likely since the precession parameter influences seasons (Berger, 1978). Between the possible modulation of the long-range transport of aerosols and that of the sources, an effect on the sources is favoured a priori, as no significant changes in transit duration have been clearly simulated for large climate changes such as between glacial and interglacial periods, while change in the seasonality may play an important role for aerosols (e.g. Werner et al., 2002).

For dust, there is evidence of insolation-driven changes dominated by precession in atmospheric circulation, but over the subtropics such as in South Brazil (Cruz et al., 2005) or in the Bolivian plateau (Fritz et al., 2004) associated with the South
American summer monsoon. Precession is also present in the cyclic variations of precipitation and weathering in northern Chile (Lamy et al., 1998). The maximum of summer insolation corresponds to evidence of a high hydrological cycle and wetter South American subtropics. The minimum of dust residuals we observed in Antarctic ice cores appears to coincide with the maximum of summer insolation, suggesting that the dust sources (e.g. Patagonia) were similarly involved and reduced.

For sodium, residual maxima appear with the maxima of summer insolation (Figs 6A and B), discarding a direct link with sea ice extent. Also, an e-folding time reduction cannot be invoked because a warmer troposphere is wetter and more cleansed. Alternatively, the sodium source strength could be better linked to cyclogenesis at mid-latitudes, both peaking during austral springtime. At spring equinoctial time, the meridional temperature gradient for the mid-latitudes reaches its maximum value as the rate of daily insolation (i.e. day length) peaks in austral spring time and the widely extended sea ice imposes a high albedo contrast with the ocean along with a sea surface temperature at freezing point at the ice edge. In this conjuncture, cyclogenesis could be associated with the rate of change insolation at mid-latitudes, the latter being proportional to summer insolation amplitude which is modulated by precession. The precession component, which is detected in EDC and Vostok sodium residuals may be the result of such an effect. For the precession signal observed in the nss- $\mathrm{SO}_{4}$ residual signal, the 


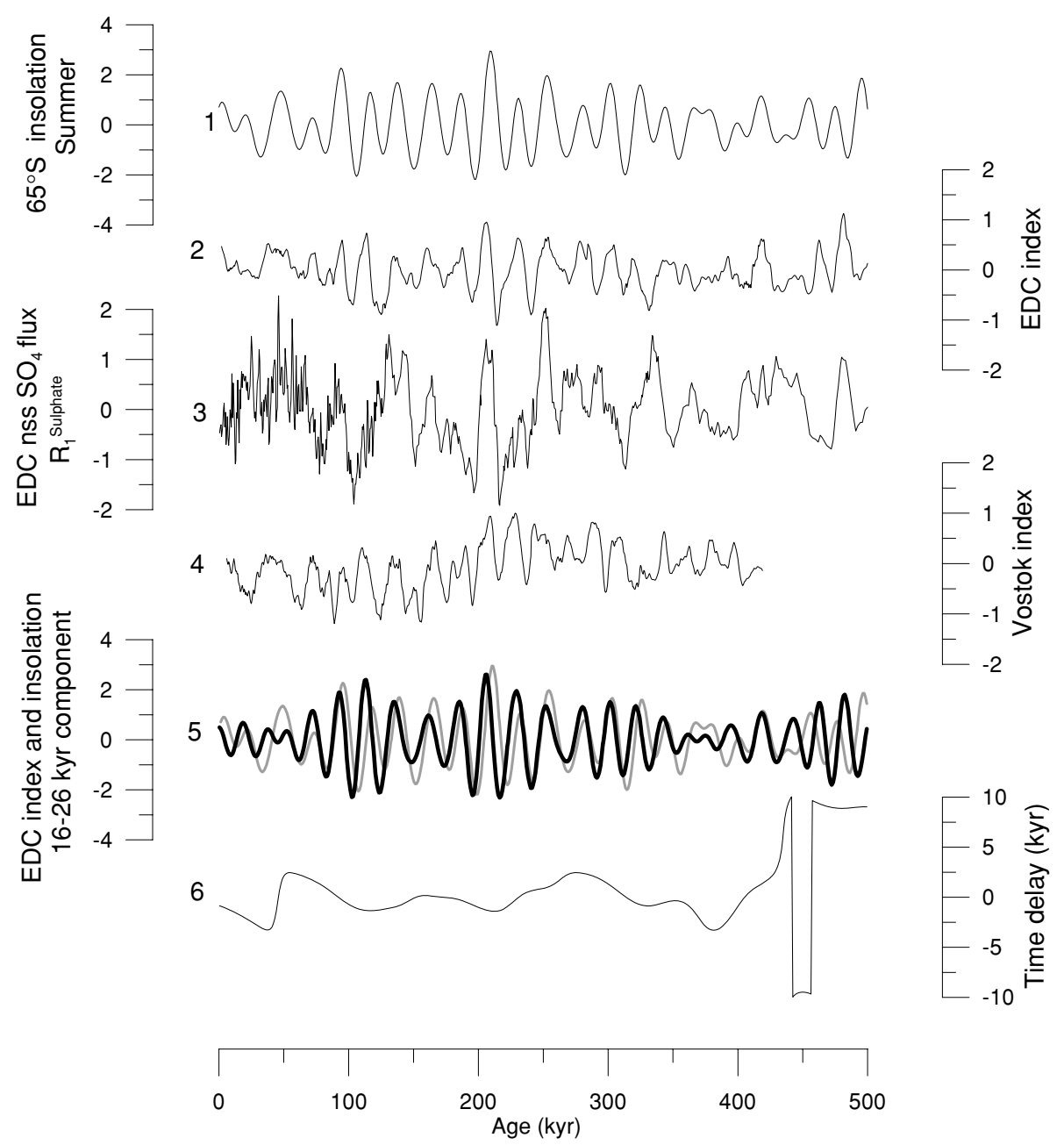

Fig. 7. Austral summer insolation along with EDC and Vostok aerosol indexes over the last $\sim 450 \mathrm{kyr}$. (1) $65^{\circ} \mathrm{S}$ summer insolation; (2) EDC aerosol index; (3) EDC sulphate flux (from Wolff et al., 2006); (4) Vostok aerosol index; (5) Precessional component (16-26 kyr) of 65 ${ }^{\circ} \mathrm{S}$ insolation (black) and EDC aerosol index (grey). The two filtered signals are consistent over the last $400 \mathrm{kyr}$ but not for prior period; (6) Phase lag (given in kyr) between processional component of $65^{\circ} \mathrm{S}$ insolation and that from aerosol index. Phase lag is significant for period prior $400 \mathrm{kyr}$. Residuals and insolation data have been normalized with respect to their mean and standard deviation. The aerosol indexes for EDC and Vostok sites have been defined from the difference between sodium and calcium (normalized) residuals and between sodium and dust (normalized) residuals, respectively. The sodium, calcium and dust data have been re-sampled $(0.5 \mathrm{kyr})$ and the aerosol index averaged by a running mean over $4 \mathrm{kyr}$. EDC and Vostok aerosol indexes are plotted against their own chronology (i.e. EDC2 EPICA Community Members, 2006) and GT4, respectively (Petit et al., 1999). Phase lag was calculated from the cross-correlation using a wavelet algorithm (Matlab ${ }^{\circledR}$ software).

interpretation is more complex (see Appendix, Section A2) and beyond the scope of this paper. The consistency of the sulphate signal with dust and sodium residuals should be kept in mind.

4.4.3. Prospects for ice core dating. The combination of sodium and dust residuals (normalized values and considering their differences to take into account their opposite behaviour) makes it possible to construct a stack record ('aerosol index') that amplifies the modulation effect and reduces the noise. Precession periodicities (around $20 \mathrm{kyr}$ ) are clearly suggested both from EDC and Vostok stack records (Fig. 7, plots 2 and 4). As a preliminary result, from a simple running mean over $4 \mathrm{kyr}$, the maxima and minima appear well coincident with the maxima and minima of $65^{\circ} \mathrm{S}$ summer insolation. The amplitude of the aerosol index closely follows the amplitude change in insolation as modulated by eccentricity and is high between 200 and $300 \mathrm{kyr}$ BP (Fig. 7, plot 2 and 4), a correspondence that also holds for the sodium and dust residuals, as well as for nss- $\mathrm{SO}_{4}$ (Fig. 7, plot 3).

The processional component (16-26 kyr filter window) of the aerosol index (Fig. 7, plot 5) indicates that the signal amplitude shows significant spectral consistency with the insolation component over the last $400 \mathrm{kyr}$ (Fig. 7, plot 6). Moreover, the 
phase lag that we can calculate from cross-correlation between $65^{\circ} \mathrm{S}$ insolation and EDC aerosol is close to zero (plus minus $3 \mathrm{ka}$ ), however it significantly increases for a period before 440 kyr BP. This demonstrates the quality of the EDC chronology (here EDC2) over the last $400 \mathrm{kyr}$ as proposed from a glaciological model (Parrenin et al., 2001; EPICA Community Members, 2006). The chronology of the deeper part requires some readjustments (Parrenin et al., 2007).

\section{Conclusion and perspectives}

An empirical model was used to reproduce the dust and marine salt concentrations in EPICA Dome $\mathrm{C}$ and Vostok ice records to within a factor of 2 and 1.2, respectively. We assume that the aerosol e-folding time, driven by wet deposition, is an important factor in the glacial-interglacial changes in aerosol concentration of polar ice, possibly accounting for a factor of 2.5 and 4 increase for sea salt and dust, respectively. The pathway of polar aerosols at high altitude within the dry and cold troposphere (e.g. $-40^{\circ} \mathrm{C}$ ) makes atmospheric cleansing very sensitive to temperature. In turn, a $3.5-5{ }^{\circ} \mathrm{C}$ decrease in the overall temperature of the high-troposphere over the Southern Ocean for last glacial period is inferred, and appears to be consistent with other estimates.

An overall mean transit time of one month was adopted for dust, based on ${ }^{222} \mathrm{Rn}$ and dust concentration studies. For sodium, a transit time of one week is adopted, partly deduced from back trajectories. Transit time plays an important role in concentration changes but is so far poorly constrained. Future aerosol monitoring at inland Antarctic stations, including radon radioactivity measurements, will be valuable in this respect.

For dust, three climatic factors (dry deposition/accumulation, life-time and source) explain up to $80 \%$ of the signal variance. From the dust-isotope relationship, two isotope climatic mode thresholds are defined. The first threshold is interpreted as a change from interglacial conditions to cooler climate $\left(\sim-1{ }^{\circ} \mathrm{C}\right)$, and a coupling between Southern Ocean and Antarctic troposphere temperature. It could be used as a criterion to define the onset and conclusion of each interglacial period. The second threshold amplifies the colder conditions $\left(\sim-4{ }^{\circ} \mathrm{C}\right)$ and the coupling so as to influence a large part of the South American continent. It can be used as a criterion for characterizing glacial conditions. Under these conditions, a third factor we associate with the source emission (ASEF) at mid-latitudes is quantitatively deduced from the isotope and dust profiles. ASEF is linked to the extent of glaciation and southern South America emissions and has amplitude of two to four times the Holocene value, consistent with other geological evidence from mid-latitudes.

Our approach offers perspectives for modelling of polar dust fallout using AGCM simulations. Aside from assumptions concerning the dominance of dry deposition for aerosol over
Antarctica and a contribution from mid-latitude dust sources, the small size of the dust particles, the dominance of the wet deposition during the peculiar pathway at high altitudes within troposphere, and a $3.5-5{ }^{\circ} \mathrm{C}$ temperature change for glacial conditions should make it possible to reproduce the LGM factor of 30-50 increase in ice core dust. In this respect, one of the possible error in AGCMs could be the too short transport duration for fine dust reaching the central plateau. For present day conditions, AGCMs transit times over the Southern Ocean up to high southern latitudes appear consistent with 5-10 d transport from air masses back trajectories (e.g. Lunt and Valdes, 2001; Reijmer et al., 2002; Krinner and Genthon, 2003) and more or less with ${ }^{222} \mathrm{Rn}$ observations at costal regions of Antarctica (e.g. Li et al., 2008). However, the small size of the Antarctic dust (with $2 \mu \mathrm{m}$ diameter for the mode of volume size distribution) and the very low ${ }^{222} \mathrm{Rn}$ radioactivity level observed at the South Pole do not support these views. Such transport duration, which likely applies for low altitude air masses (and marine aerosols) may not be valid for the continental air masses (and the fine fraction of the dust) originating from South America which effectively reach the Antarctic plateau. By contrast, if we adopt with Maenhault et al. (1979) and Yung et al. (1996) a transit time of one month for present climate, that we also use for glacial conditions, the effect of the atmospheric cleansing becomes considerably amplified giving a significant change in the transport efficiency of the dust. Further aerosols monitoring at central stations of Antarctica will help better constraining simulations of the dust cycle for present conditions.

Sodium is closely linked to temperature, and when dry deposition/accumulation factor is used together with the life-time factor, it explains up to $90 \%$ of the variance. The remaining $10 \%$ of the variance contains orbital periodicities. Our approach cannot disentangle a sodium source that is not correlated with the isotope composition of precipitation. Caution should be therefore exerted when using sodium as an independent indicator of sea ice extent around Antarctica. Sea ice area should be first linked to the Antarctic temperature (isotope) as a result of the permanent interactions and temperature couplings between Antarctica and the surrounding ocean; simultaneously its latitudinal extent amplifies the meridional temperature gradient and therefore amplifies cyclogenesis. The sodium fluxes to Antarctica are linked to temperature through the aerosol e-folding time change. Our approach suggests that the atmospheric sodium load of the upper troposphere in sub-Antarctic regions is constant, within a second-order orbital modulation, whatever the climate. In addition, a glacial-interglacial temperature change in the low-troposphere temperature over the polar front region is suggested to be of similar amplitude $\left(\sim-5-7^{\circ} \mathrm{C}\right)$ to that of the inversion layer over the Antarctic plateau.

The residuals of impurity signals appear to be modulated by the orbital precession, but in opposite ways for dust and sodium residuals. For the dust sources, a modulation is possible assuming some link between the moisture advection by the 
southern America monsoon over the subtropics and that over the southern part of South America (e.g. Patagonia), both of which tend to reduce dust emission. Sodium residuals appear consistent with austral summer insolation, a conjuncture, which cannot be linked to sea ice extent. Instead, adopting cyclogenesis as a source agent, increased emission with insolation (and precession) is likely. Concerning sodium from secondary emission of the frost flowers which form at the sea ice surface, monitoring of the chemical content of air over an Antarctic inland site, such as the program underway at the Italian-French station of Concordia (Jourdain et al., 2008), may help solve this issue.

The consistency of the signal included within the dust and sodium residuals is also present for the sulphate residual and, together with results for other chemistry components that will be soon available at high resolution (e.g. Bigler et al., 2006; Lambert et al., 2008) over the 8 climatic cycles of EDC, may serve to build a 'chemistry pacemaker' that can be used along with ${ }^{18} \mathrm{O}$ from $\mathrm{O}_{2}$ and total air volume from bubbles preserved in the ice (Dreyfus et al., 2007; Raynaud et al., 2007) to refine existing ice core chronologies.

\section{Acknowledgments}

We thank M. Legrand, M. de Angelis, R. Gersonde, F. Lambert, A. Martinez-Garcia for providing access to unpublished data; B. Lemieux-Dudon, M. Debret and H. Gallée for help; M. Hutterli, E. Wolff, H. Fisher, G Delaygues for fruitful discussions; M. Town and the anonymous reviewers for their suggestions improving the manuscript.

This study was supported by the French ANR project PICC. This work is a contribution to the 'European Project for Ice Coring in Antarctica' (EPICA), a joint ESF (European Science Foundation)/EC scientific programme, funded by the European Commission under the Environmental and Climate Programme (1994-1998) contract ENV4-CT95-0074 and by national contributions from Belgium, Denmark, France, Germany, Italy, the Netherlands, Norway, Sweden, Switzerland and the United Kingdom.

This is EPICA publication number 229.

\section{Appendix}

\section{A.1. Linking aerosol e-folding time and atmospheric water content in AGCMs}

Wet deposition includes collision and nucleation scavenging, and with respect to the atmospheric load of an atmospheric layer $\left(M_{1}\right)$, it is parametrized in AGCMs as follows (e.g. Genthon, 1992)

$\Delta M_{1}=M_{1}\left[1-\exp \left(-\alpha Q_{1} \Delta t\right)\right]$ where $\Delta M_{1}$ represents the scavenged portion from atmospheric layer 'l' during time interval $\Delta t, \alpha$ a coefficient depending on the removal processes and the particles size and $Q_{1}$ the precipitation from the layer or from the layer above. Within the high troposphere, $Q_{1}$ is likely very small because of very dry and cold conditions. Therefore, assuming $\alpha Q_{1} \Delta t \ll 1$, the remaining part of the atmospheric load $(\Delta A)$ which could further supply the Antarctic atmosphere could be written

$\Delta A=M_{1}-\Delta M_{1} \sim A\left(-\alpha Q_{1} \Delta t\right)$

and after integration

$A \sim A_{0} \exp \left(-\alpha^{\prime} Q t\right)$

where $Q$ is an overall mean precipitation rate we can associate with the hydrological cycle, $\alpha^{\prime}$ a mean scavenging coefficient and $A_{0}$ the atmospheric dust load over the source at mid-latitudes. Comparing (A3) to eq. (5) from the text $\left[C=C_{0} \exp (-t+t / \tau)\right]$ and assuming $\alpha^{\prime}$ constant, we can assign the transit time ' $t \_t$ ' to ' $t$ ', and the e-folding time ' $\tau$ ' to the overall precipitation rate ' $Q$ ' giving

$\tau \sim(Q)^{-1}$.

\section{A.2. Sulphate record of the EPICA Dome C ice core}

The scatter plot of the nss-SO $\mathrm{SO}_{4}$ from EDC (Wolff et al., 2006) concentration and flux versus isotope content is reported in Figs $3 \mathrm{~F}_{0}$ and $\mathrm{F}_{1}$. The nss- $\mathrm{SO}_{4}$ flux (or residual $\mathrm{R}_{1}$ from our model) appears to be no longer dependent on climate but in the time domain the profile (normalized values) also suggests orbital frequencies at precession (Fig. 6, upper panel) and its variability is very similar to that of the sodium residual. At Vostok, the nss- $\mathrm{SO}_{4}$ flux has a very different behaviour and the calculated spectral coherency with sodium suggests an absence of common behaviour (Legrand et al., 1988; and personal communication), as a probable consequence of its interaction with other aerosols (i.e. mostly the sea salt), as air masses age and descent from the stratosphere. Note that nss- $\mathrm{SO}_{4}$ aerosol is mostly sulphuric acid (Legrand and Delmas, 1988) and Vostok is a site under less ocean influence than EDC, as is also suggested by the lower accumulation rate $(\sim 30 \%)$ and more depleted isotope composition $(-440 \%$ instead $-400 \%$ ) for snow precipitations. The record of the nss- $\mathrm{SO}_{4}$ flux from EDC contains prominent precession periodicities (Fig. 7, plot 3 ) while data reduction is limited to the accumulation factor.

The nss- $\mathrm{SO}_{4}$ at EDC, mostly results from oxidation of DMS emitted by ocean biological productivity (Wolff et al., 2006), which shows a strong seasonal cycle peaking in summer in coastal areas (Minikin et al., 1998). The apparent nss-SO $\mathrm{SO}_{4}$ variability at precession periodicities may reflect the modulation of ocean productivity assuming constant ageing processes and transport, amongst other scenarios. 


\section{References}

Aitchison, J. and Brown, J. A. C. 1957. The Log Normal Distribution with Special Reference to its uses in Economics. Cambridge University, London, 176.

Alley, R. B., Finkel, R. C., Nishiizumi, K., Anandakrishnan, S., Shuman, C. A. and co-authors. 1995. Changes in continental sea-salt atmospheric loadings in central Greenland during the most recent deglaciation: model-based estimates. J. Glaciol. 41, 503-514.

Andersen, K. K., Armengaud, A. and Genthon, C. 1998. Atmospheric dust under glacial and interglacial conditions. Geophys. Res. Lett. 25, 2281-2284.

Balkanski, Y., Jacob, D. J., Gardner, G. M., Graustein, W. C. and Turekian, K. K. 1993. Transport and residence times of tropospheric aerosols inferred from a global three-dimensional simulation of ${ }^{210} \mathrm{~Pb}$. J. Geophys. Res. 98, 20573-20586.

Basile, I., Grousset, F. E., Revel, M., Petit, J. R., Biscaye, P. E. and co-authors. 1997. Patagonian origin of glacial dust deposited in East Antarctica (Vostok and Dome C) during glacial stages 2, 4 and 6. Earth Planet. Sci. Lett. 146, 573-57.

Berger, A. 1978. Long-term variations of daily insolation and Quaternary climatic changes. J. Atmos. Sci., 35, 2362-2367.

Bigler, M., Rothlisberger, R., Lambert, F., Stocker, T. F. and Wagenbach, D. 2006. Aerosol deposited in East Antarctica over the last glacial cycle: detailed apportionment of continental and sea-salt contributions. J. Geophys. Res. 111, D08205, doi:10.1029/2005JD006469.

Brathauer, U. and Abelmann, A. 1999. Late Quaternary variations in sea surface temperatures and their relationship to orbital forcing recorded in the Southern Ocean (Atlantic sector). Paleoceanography 14, 135148.

Castellano, E., Becagli, S., Jouzel, J., Migliori, A., Severi, M. and coauthors. 2004. Volcanic eruption frequency over the last $45 \mathrm{ky}$ as recorded in the Epica-Dome C ice core (East Antarctica) and its relationship with climatic changes. Global Planet. Change 42, 195-205.

Charlesworth, J. K. 1957. The Quaternary Era. Edward Arnold, London, 1700.

Chylek, P., Lesins, G. and Lohmann, U. 2001. Enhancement of dust source area during past glacial periods due to changes of the Hadley circulation. J. Geophys. Res., 106, 18477-18485.

Cruz Jr., F. W., Burns, S. J., Karmann, I., Sharp, W. D., Vuille, M. and co-authors. 2005. Insolation-driven changes in atmospheric circulation over the past 116,000 years in subtropical Brazil. Nature $\mathbf{4 3 4}$, 63-66.

Cunningham, W. C. and Zoller, W. H. 1981. The chemical composition of remote area aerosols. J. Aerosol Sci. 12, 367-384.

Curran, M., Wong, G., Goodwin, I., van Ommen, T. and Vance, T. 2008. Estimate of sea salt sources to Antarctica: an alternative interpretation of the EPICA sea salt record? Geophys. Res. Abstr., 10, A07581 .

Delmonte, B., Petit, J. R. and Maggi, V. 2002. Glacial to Holocene implications of the new 27,000 year dust record from the EPICA Dome C (East Antarctica) ice core. Clim. Dyn. 18, 647-660.

Delmonte, B., Petit, J. R., Andersen, K. K., Basile-Doelsch, I., Maggi, V. and co-authors. 2004a. Opposite regional atmospheric circulation changes over east Antarctica during the last climatic transition evidenced by dust size distributions changes. Clim. Dyn., 23, 427-438, doi:10.1007/s00382-004-0450-9.
Delmonte, B., Basile-Doelsch, I., Petit, J. R., Maggi, V., RevelRolland, M. and co-authors. 2004b. Comparing the EPICA and Vostok dust records during the last 220,000 years: stratigraphical correlation and provenance in glacial periods. Earth Sci. Rev. 66, 63-87.

Dreyfus, G. B., Parrenin, F., Lemieux-Dudon, B., Durand, G., MassonDelmotte, V. and co-authors. 2007. Anomalous flow below 2700 $\mathrm{m}$ in the EPICA Dome $\mathrm{C}$ ice core detected using $\delta^{18} \mathrm{O}$ of atmospheric oxygen measurements. Clim. Past - CPD 3, 341353.

EPICA Community Members. 2004. Eight glacial cycles from an Antarctic ice core. Nature 429, 623-628.

EPICA Community Members. 2006. One-to-one coupling of polar climate variability. Nature 444, 195-198.

Fischer, H., Sigaard-Andersen, M. L., Ruth, U., Rothlisberger, R. and Wolff, E. 2007a. Glacial/interglacial changes in mineral dust and seasalt records in polar ice cores: sources, transport and deposition. Rev. Geophys. 45, RG1002/2007, 1-26.

Fischer, H., Fundel, F., Ruth, U., Twarloh, B., Wegner, A. and co-authors. 2007b. Reconstruction of millennial changes in dust emission, transport and regional sea ice coverage using the deep EPICA ice cores from the Atlantic and Indian Ocean sector of Antarctica. Earth Planet. Sci. Lett. 260, 340-354.

Franois, R., Altabet, M. A., Yu, E. F., Sigman, D. M., Bacon, M. P., Frank, M. and co-authors. 1997. Contribution of Southern Ocean surfacewater stratification to low atmospheric $\mathrm{CO}_{2}$ concentrations during the last glacial period. Nature 389, 929-935, doi:10.1038/40073.

Fritz, S. C., Baker, P. A., Lowenstein, T. K., Seltzer, G. O., Rigsby, C. A. and co-authors. 2004. Hydrologic variation during the last 170,000 years in the southern hemisphere tropics of South America. Quater. Res. 61, 95-104.

Fuhrer, K., Wolff, E. W. and Johnsen, S. J. 1999. Timescales for dust variability in the Greenland Ice Core Project (GRIP) ice core in the 100,000 years. J. Geophys. Res. 104, 31043-31052, doi:10.1029/1999JD900929.

Gaiero, D. M. 2007. Dust provenance in Antarctic ice during glacial periods: From where in southern South America? Geophys. Res. Lett. 34, L17707, doi:10.1029/2007GL030520.

Genthon, C. 1992. Simulations of desert dust and sea-salt aerosols in Antarctica with a general circulation model of the atmosphere. Tellus 44B, 371-389.

Genthon, C. and Armengaud, A. 1995. Radon 222 as a comparative tracer of transport and mixing in two general circulation models of the atmosphere. J. Geophys. Res. 100, 2849-2866.

Hansson, M. 1995. Are changes in atmospheric cleansing responsible for observed variations of impurity concentrations in ice cores? Ann. Glaciol. 21, 219-22.

Hansson, M. 1996. Atmospheric residence times influence on tracer concentrations in remote polar areas. In: Chemical Exchange between the Atmosphere and Polar Snow (eds E. Wolff and R. Bales). SpringerVerlag, Berlin Heidelberg, 582-585.

Hara, K., Osada, K., Kido, M., Hayashi, M., Matsunaga, K. and coauthors. 2004. Chemistry of sea-salt particles and inorganic halogen species in Antarctic regions: compositional differences between coastal and inland stations. J. Geophys. Res. 109, D20208, doi:10.1029/2004JD004713.

Hoskins, B. and Pearce, R. (ed). 1983. Large-scale Dynamical Processes in the Atmosphere, Academic Press, London, 397. 
IPCC. 2007. Climate Change 2007: the physical science basis. Contribution of Working Group I to the Fourth Assessment Report of the Intergovernmental Panel on Climate Change (eds S. Solomon, D. Qin, M. Manning, Z. Chen, M. Marquis, and co-editors). Cambridge University Press, Cambridge, United Kingdom and New York, NY, USA.

Jacob, D. J., Prather, M. J., Boville, B. A., Rasch, P. J., Feichter, J. and co-authors. 1997. Intercomparison of convective and synoptic transport in global models using ${ }^{222} \mathrm{Rn}$ and other tracers. J. Geophys. Res. 102, 5953-5970.

Jourdain, B., Preunkert, S., Cerri, O., Castebrunet, H., Udisti, R. and co-authors. 2008. Year-round record of size-segregated aerosol composition in central Antarctica (Concordia station): implications for the degree of fractionation of sea-salt particles. J. Geophys. Res. 113, D14308, doi:10.1029/2007JD009584.

Joussaume, S. 1989. Desert dust and climate: an investigation using an atmospheric general circulation model. In: Paleoclimatology and Paleometeorology: Modern and Past Patterns of Global Atmospheric Transport. (eds M. Leinen and M. Sarnthein) NATO Workshop, 253263.

Jouzel, J., Lorius, C., Petit, J. R., Genthon, C., Barkov, N. I. and coauthors. 1987. Vostok ice core: a continuous isotope temperature record over the last climatic cycle (160,000 years). Nature 329, 402408.

Jouzel, J., Benoist, J. P., Yiou, F., Lorius, C., Raynaud, D. and co-authors. 1989. A comparison of deep Antarctic ice cores and their implications for climate between 65,000 and 15,000 years ago. Quater. Res. 31, $135-150$.

Jouzel, J., Vaikmae, R., Petit, J. R., Martin, M., Duclos, Y. and coauthors. 1995. The two-step shape and timing of the last deglaciation in Antarctica. Clim. Dyn. 11, 151-161.

Jouzel, J., Masson-Delmotte, V., Cattani, O., Dreyfus, G., Falourd, S. and co-authors. 2007. Orbital and millennial antarctic climate variability over the past 800,000 years. Science 317, 793-796, doi:10.1126/science.1141038.

Junge, C. E. 1963. Air Chemistry and Radioactivity. Academic Press, New York, 382.

Kohfeld, K. and Harrison, S. P. 2001. DIRTMAP: the geological record of dust. Earth Sci. Rev. 54, 81-114.

Krinner, G. and Genthon, C. 1998. GCM simulations of the Last Glacial Maximum surface climate of Greenland and Antarctica. Clim. Dyn. 14, 741-758.

Krinner, G. and Genthon, C. 2003. Tropospheric transport of continental tracers towards Antarctica under varying climatic conditions. Tellus 55B, 54-70.

Kumar, N., Anderson, R. F., Mortlock, R. A., Froelich, P. N., Kubik, P. and co-authors. 1995. Increased biological productivity and export production in the glacial Southern Ocean. Nature 378, 675680.

Lambert, G., Polian, G. and Taupin, D. 1970. Existence of periodicity in radon concentrations and in the large-scale circulation at latitudes between $40^{\circ}$ and $70^{\circ}$ south. J. Geophys. Res. 75, 2341-2345.

Lambert, F., Delmonte, B. Petit, J. R., Bigler, M., Kaufmann, P. R. and co-authors. 2008. Dust-climate couplings over the past 800,000 years from the EPICA Dome C ice core. Nature 452, 616-619.

Lamy, F., Hebbeln, D. and Wefer, G. 1998. Late Quaternary processional cycles of terrigenous sediment input off the Norte Chico, Chile $\left(27.5^{\circ} \mathrm{S}\right)$ and paleoclimatic implications. Palaeogeog. Palaeoclim. Palaeoecol. 141, 233-251.

Lamy, F., Kaiser, J., Ninnemann, N., Hebbeln, D., Arz, H. W. and co-authors. 2004. Antarctic timing of surface water changes off Chile and Patagonian ice sheet response. Science 304, 19591962.

Lea, D., Pak, D. K., Peterson, I. C. and Hughen, K. 2003. Synchroneity of tropical and high latitude temperature over the last glacial termination. Science 301, 136-1364.

Legrand, M. and Delmas, R. 1988. Formation of $\mathrm{HCl}$ in the Antarctic atmosphere. J. Geophys. Res. 93, 7153-7168.

Legrand, M. and Kirchner, S. 1988. Polar atmospheric circulation and chemistry of recent (1957-1983) south polar precipitation. Geophys. Res. Lett. 15, 879-882.

Legrand, M. and Mayewski P. 1997. Glaciochemistry of polar ice cores: a review. Rev. Geophys. 35, 219-243.

Legrand, M., Lorius, C., Barkov, N. I. and Petrov, V. N. 1988. Atmospheric chemistry changes over the last climatic cycle $(160,000 \mathrm{yr})$ from Antarctic ice. Atmos. Environ. 22, 317-331.

Li, F., Ginoux, P. and Ramaswamy, V. 2008. Distribution, transport, and deposition of mineral dust in the Southern Ocean and Antarctica: contribution of major sources. J. Geophys. Res. 113, D10207, doi:10.1029/2007JD009190.

Lorius, C., Jouzel, J., Raynaud, D., Hansen, J. and Le Treut, H. 1990. Greenhouse warming, climate sensitivity and ice core data. Nature 347, 139-145.

Lunt, D. J. and Valdes P. J. 2001. Dust transport to Dome C, Antarctica, at the last glacial maximum and at the present day. Geophys. Res. Lett. 28, 295-298.

Maenhaut, W., Zoller, W. H. and Coles, D. G. 1979. Radionuclides in the South Pole atmosphere. J. Geophys. Res. 84, 31313138.

Mahowald, N., Kohfeld, K., Hansson, M., Balkanski, Y., Harrison, S. P. and co-authors. 1999. Dust sources and deposition during the Last Glacial Maximum and current climate: a comparison of model results with paleodata from ice cores and marine sediments. J. Geophys. Res. 104, 15895-15916.

Mahowald, N. M., Muhs, D. R., Levis, S., Rasch, P. J., Yoshioka, M. and co-authors. 2006. Change in atmospheric mineral aerosols in response to climate: last glacial period, preindustrial, modern, and doubled carbon dioxide climates, J. Geophys. Res. 111, D10202, doi:10.1029/2005JD006653.

Martin, J. H. 1990. Glacial-interglacial $\mathrm{CO}_{2}$ change: the iron hypothesis. Paleoceanography 5, 1-13.

Martínez-Garcia, A., Rosell-Melé, A., Geibert, W., Masqué, P., Gersonde, R. and co-authors. 2008. Links between iron supply, marine productivity, sea surface temperature and $\mathrm{CO}_{2}$ over the last 1.1 Myr. Paleoceanography 24, PA1207, doi:10.1029/2008PA001657.

Minikin, A., Legrand, M., Hall, B. L., Wagenbach, D., Kleefeld, C. and co-authors. 1998. Sulfur-containing species (sulfate and methanesulfonate) in coastal Antarctic aerosol and precipitation. J. Geophys. Res., 103, 10927-10934.

Narcisi, B., Petit, J. R., Delmonte, B., Basile-Doelsch, I. and Maggi V. 2005. Characteristics and sources of tephra layers in the EPICA-Dome $\mathrm{C}$ ice record (East Antarctica): implications for past atmospheric circulation and ice core stratigraphic correlations. Earth Planet. Sci. Lett. 239, 253-265. 
Noone, D. and Simmonds, I. 2002. Annular variation in moisture transport mechanisms and abundance of $\delta^{18} \mathrm{O}$ in Antarctic snow. $J$. Geophys. Res. 107, 4742. doi:10.1029/2002JD002262.

North GRIP Community Members. 2004. High resolution climate record of the northern hemisphere reaching into last interglacial period. Nature 431, 147-151.

Pahnke, K. and Zahn, R. 2005. Southern Hemisphere water mass conversion linked with North Atlantic climate variability. Science 307, 1741-1746, doi:10.1126/science.1102163.

Paillard, D., Labeyrie, L. D. and Yiou, P. 1996. Macintosh program performs time-series analysis. EOS Trans. Am Geophys. Un. 77, 379.

Parrenin, F., Jouzel, J., Welbroeck, C., Ritz, C. and Barnola, J. M. 2001. Dating the Vostok ice core by an inverse method. J. Geophys. Res. 106, 31837-31851.

Parrenin, F., Barnola, J.-M., Beer, J., Blunier, T., Castellano, E. and co-authors. 2007. The EDC3 chronology for the EPICA Dome C ice core. Clim. Past 3, 485-497.

Petit, J. R., Briat, M. and Royer, A. 1981. Ice Age aerosol content from East Antarctic ice core samples and past wind strength. Nature 293, 391-394.

Petit, J. R., Mounier, L., Jouzel, J. and Korotkevich Y. S. 1990. Paleoclimatological and chronological implications of the Vostok core dust record. Nature 343, 56-58.

Petit, J. R., Jouzel, J., Raynaud, D., Barkov, N. I., Barnola, J. M. and co-authors. 1999. Climate and atmospheric history of the past 420000 years from the Vostok ice core, Antarctica. Nature 399, 429-436.

Pye, K. 1987. Aeolian Dust and Dust Deposits. Academic Press. London, 334.

Ramonet, M., Le Roulley, J. C., Bousquet, P. and Monfray, P. 1996. Radon-222 measurements during the Tropoz II campaign and comparison with a global atmospheric transport model. J. Atmos. Chem. 23, 107- 136.

Rankin, A. M., Wolff, E. W. and Martin, S. 2002. Frost flowers: implications for tropospheric chemistry and ice core interpretation. J. Geophys. Res. 107, 4683, doi:10.1029/2002JD002492.

Raynaud, D., Jouzel, J., Barnola, J. M., Chappellaz, J., Delmas, R. J. and co-authors. 1993. The ice record of greenhouse gases. Science 259, 926-933.

Raynaud, D., Lipenkov, V., Lemieux-Dudon, B., Duval, P., Loutre, M. F. and Lhomme N. 2007. The local insolation signature of air content in Antarctic ice:a new step toward an absolute dating of ice records. Earth Planet. Sci. Lett. 261, 337-349.

Reijmer, C. H., Van Den Broeke, M. R. and Scheele, M. P. 2002. Air parcel trajectories and snowfall related to five deep drilling locations in Antarctica based on the ERA-15 Dataset. J. Clim. 15, 19571968.

Ritz, C. 1992. Un modèle thermo-mécanique d'evolution pour le basin glaciaire antarctique Vostok-glacier Byrd: sensibilité aux valeurs des paramètres mal connus. Thesis, Univ. Joseph Fourier Grenoble 1, France.
Ruth, U., Wagenbach, D., Steffensen, J. P. and Bigler, M. 2003. Continuous record of microparticle concentration and size distribution in the central Greenland NGRIP ice core during the last glacial period. J. Geophys. Res. 108, 4098-4110.

Schwander, J., Jouzel, J., Hammer, C. U., Petit, J. R. and co-authors. 2001. A tentative chronology for the Epica Dome C Concordia ice recor. Geophys. Res. Lett. 28, 4243-4246.

Schwerdtfeger, W. 1984. Weather and Climate in the Antarctic. Elsevier Science, Amsterdam, 261.

Steffensen, J. P. 1997. The size distribution of microparticles from selected segments of the GRIP ice core representing different climatic periods. J. Geophys. Res. 102, 26755-26763.

Stenni, B., Masson-Delmotte, V., Johnsen, S., Jouzel, J., Longinelli, A. and co-authors. 2002. An oceanic cold reversal during the last deglaciation. Science 293, 2074-2077.

Stocker, T., Johnsen, S. and Anandakrishnan, S. 2003. A minimum thermodynamic model of the bipolar seesaw. Paleoceanography $\mathbf{1 8}$ doi:10.1029/2003PA000920.

Stute, M., Forster, M., Frischkorn, H., Serejo, A. Clark, J. F. and coauthors. 1995. Cooling of Tropical Brazil $\left(5^{\circ} \mathrm{C}\right)$ during the last glacial maximum. Science 269, 379-383.

Tuncel, G., Aras, N. K. and Zoller, W. H. 1989. Temporal variations and sources of elements in the South Pole atmosphere 1. Nonenriched and moderately enriched elements. J. Geophys. Res. 94, 1302513038 .

Watanabe, O., Jouzel, J., Johnsen, S., Parrenin, F., Shoji, H. and co-authors. 2003. Homogeneous climate variability across East Antarctica over the past three glacial cycles. Nature 422, 509512.

Werner, M., Tegen, I., Harrison, S., Kohfeld, K., Prentice, I. C. and co-authors. 2002. Seasonal and interannual variability of the mineral dust cycle under present and glacial climate conditions. J. Geophys. Res. 107, 4744, doi:10.1029/2002JD002365.

Winckler, G., Anderson, R. F., Fleisher, M. Q., McGee, D. and Mahowald, N. 2008. Covariant glacial-interglacial dust fluxes in the equatorial Pacific and Antarctica. Science 320, 93-96, doi:10.1126/science.1150595.

Wolff, E. W., Rankin, A. M. and Rothlisberger, R. 2003. An ice core indicator of Antarctic sea ice production? Geophys. Res. Lett. 30, 2158, doi:10.1029/2003GL018454.

Wolff, E. W., Fischer, H., Fundel, F., Ruth, U., Twarloh, B. and co-authors. 2006. Southern Ocean sea-ice extent, productivity and iron flux over the past eight glacial cycles. Nature 440, doi:10.1038/nature04614.

Yung, Y. L., Lee, T., Wang, C. H. and Shieh, Y. T. 1996. Dust: a diagnostic of the hydrologic cycle during the Last Glacial Maximum. Science 271, 962-963.

Zdanowicz, C., Hall, G., Vaive, J., Amelin, Y., Percival, J. and co-authors. 2006. Asian dust fall in the St Elias Mountains,Yukon, Canada. Geochem. Cosmochem. Acta 70, 3493-3507. 